\title{
Olfactory dysfunction in the pathophysiological continuum of dementia
}

\author{
Praveen Bathini ${ }^{\mathrm{a}}$, Emanuele Brai ${ }^{\mathrm{b}}$, Lavinia Alberi Auber ${ }^{\mathrm{a}, \mathrm{c}, *}$ \\ ${ }^{a}$ Department of Medicine, University of Fribourg, Fribourg, Switzerland \\ ${ }^{\mathrm{b}}$ VIB-KU Leuven Center for Brain \& Disease Research, Laboratory for the Research of Neurodegenerative Diseases, Leuven, Belgium \\ ${ }^{\mathrm{c}}$ Swiss Integrative Center of Human Health, Fribourg, Switzerland
}

\section{A R T I C L E I N F O}

\section{Keywords:}

Olfaction

Smell loss

Olfactory nerve

Aging

Dementia

Alzheimer's disease

Microbes

Inflammation

Olfactory diagnostics

\begin{abstract}
A B S T R A C T
Sensory capacities like smell, taste, hearing, vision decline with aging, but increasing evidence show that sensory dysfunctions are one of the early signs diagnosing the conversion from physiological to pathological brain state. Smell loss represents the best characterized sense in clinical practice and is considered as one of the first preclinical signs of Alzheimer's and Parkinson's disease, occurring a decade or more before the onset of cognitive and motor symptoms. Despite the numerous scientific reports and the adoption in clinical practice, the etiology of sensory damage as prodromal of dementia remains largely unexplored and more studies are needed to resolve the mechanisms underlying sensory network dysfunction. Although both cognitive and sensory domains are progressively affected, loss of sensory experience in early stages plays a major role in reducing the autonomy of demented people in their daily tasks or even possibly contributing to their cognitive decline. Interestingly, the chemosensory circuitry is devoid of a blood brain barrier, representing a vulnerable port of entry for neurotoxic species that can spread to the brain. Furthermore, the exposure of the olfactory system to the external environment make it more susceptible to mechanical injury and trauma, which can cause degenerative neuroinflammation. In this review, we will summarize several findings about chemosensory impairment signing the conversion from healthy to pathological brain aging and we will try to connect those observations to the promising research linking environmental influences to sporadic dementia. The scientific body of knowledge will support the use of chemosensory diagnostics in the presymptomatic stages of $\mathrm{AD}$ and other biomarkers with the scope of finding treatment strategies before the onset of the disease.
\end{abstract}

\section{Introduction}

Alzheimer's disease (AD), the most common type of dementia, is a rogressive neurodegenerative pathology affecting 50 million people worldwide (World Alzheimer Reports, 2018) and no curative therapy is currently available. In the last two decades only one palliative drug, memantine, was approved, while $99.6 \%$ of the clinical trials for disease-modifying drugs have failed partially as a result of the advanced staging of the patient cohorts and the reductionist focus on late phase biomarkers. Dementia has an inherent problem, its characteristic cognitive and executive symptoms, are typically diagnosed late in the disease progression at a time when irreversible processes have already set in (Fig. 1A). This mental disorder should be considered not as one disease but as a pathophysiological continuum of sequential events starting decades before the onset of the clinical symptoms. Based on the complexity and the latency of the pathology still little is known about the processes occurring in the asymptomatic phase. Currently, diagnosis of AD entails cognitive, psychological, functional imaging testing and confirmation by molecular detection of Amyloid- $\beta$ (A $\beta$ ) and tau species in cerebrospinal fluid (CSF). It is, therefore, expected that the amnestic phase of the disorder remains long underdiagnosed limiting the possibility for any reversal and restricting the eligible patient population for early therapeutics. Due to the intrinsic pathophysiological dynamic of dementia and the reductionist view of one target-one disease, we are currently lacking a proper understanding of the early mechanistic changes occurring in the pre-symptomatic stage. This is further aggravated by the fact that the current transgenic mouse models of AD mimic genetic AD pathophysiology but not its more frequent sporadic form (95\% of the cases). The dramatic lack of reproducibility between rodents and humans emphasizes the need to decomposing complex behavior and molecular events in humans to distinguish between healthy and pathological aging. As such, the development of biomarkers in early stages or in preclinical AD would

* Corresponding author at: Swiss Integrative Center for Human Health, Fribourg, Switzerland.

E-mail address: lavinia.alberi@unifr.ch (L.A. Auber). 
A

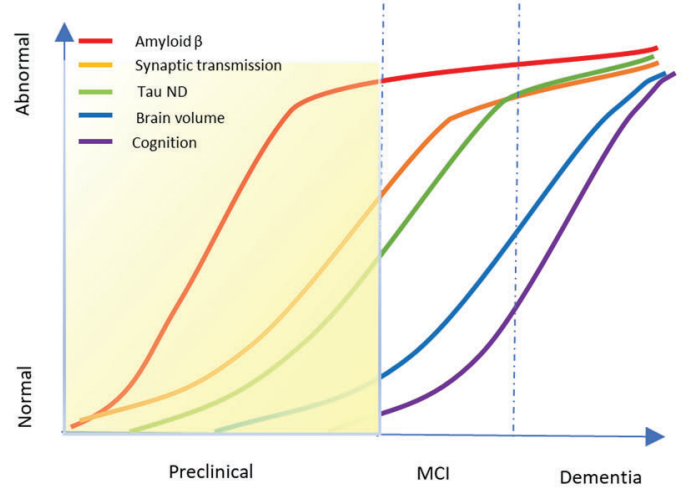

B

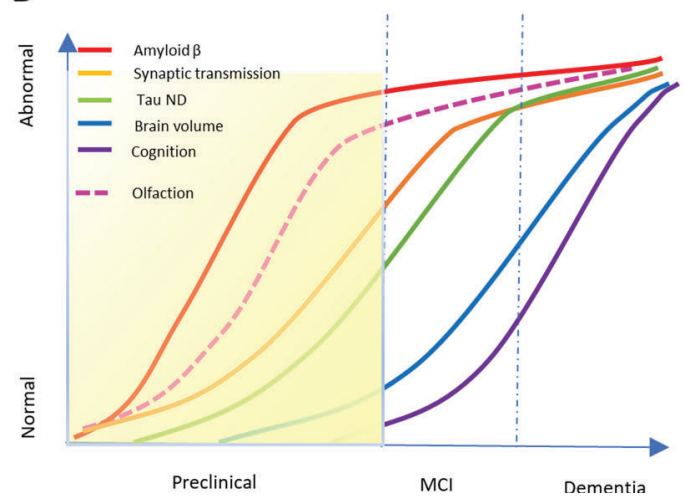

Fig. 1. Dynamic biomarkers' model underlying the progressive staging of dementia. A) Graphical sketch of the typical progression of known biomarkers in progression of dementia, with the yellow area indicating the preclinical phase. B) Graphical sketch supplemented with chemosensory decline detectable in the preclinical phase of dementia. Redrawn from Alzheimer's and Dementia Vol 7-3, 2011.

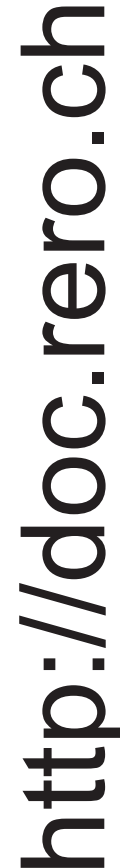
increase chances of interventions thereby decreasing the risk of future cognitive decline (Budson and Solomon, 2012).

The suggested framework of preclinical AD combines three main stages: 1) asymptomatic amyloidosis, 2) amyloidosis and neurodegeneration and 3) development of subtle cognitive changes leading to mild cognitive impairment (Sperling et al., 2011). Interestingly, our senses (smell, hearing and vision) that allow us to communicate with the external environment, while declining naturally with aging, have been shown to be prodromal of dementia (Fig. 1B). Substantial research shows the presence of Amyloid- $\beta$ and tau pathology in the central sensory and motor domains in AD patients with few sensory circuitries also being affected peripherally (Arnold et al., 2010; Christen-Zaech et al., 2003; Goldstein et al., 2003; Lewis et al., 1987). Despite the numerous clinical studies indicating that sensory dysfunction precedes cognitive loss, the generalized sensory impairment in several forms of dementia, has refrained the investigation of a mechanistic relationship between sensory and cognitive deficit leaving these studies mainly observational and correlative. The nasal neuroepithelium and the eye are the only CNS appendices in direct communication with the external environment without an interlining blood brain barrier (BBB), therefore representing a susceptible port of entry for exogenous toxins to the brain. This hypothesis is supported by the accumulation of microbial species in AD brains (Itzhaki et al., 2016). Furthermore, in these areas, host-pathogen interactions gain particular importance as peripheral inflammatory responses are propagated to the CNS without anatomical impediment. Noteworthy, several gene variants, including Apolipoprotein E type epsilon 4 (ApoE\&4), identified as risk factors for $\mathrm{AD}$, play a major role in inflammatory responses (Zhang et al., 2011), suggesting a common mechanistic link between environmental adaptive processes and network dysfunction that could unfold through the sensory organs. While vision and hearing are just beginning to emerge as clinically relevant for $\mathrm{AD}$, chemosensory impairment is established in $\mathrm{AD}$ foreplay and $\mathrm{AD}$ progression.

This review focuses on olfactory impairment as preclinical indicator of dementia and contains the most updated collection of clinical and preclinical studies treating olfactory processing in the context of brain aging and neurodegenerative diseases. The aim of this manuscript is to provide the foundation for associating the infectious hypothesis of $\mathrm{AD}$ to early chemosensory impairment (Fig. 2) and emphasize the great potential of olfaction as prognostic non-invasive behavioral signature to classify preclinical AD.

\section{Anatomy of the olfactory system in AD}

\subsection{Primary olfactory area}

\subsubsection{Nasal cavity}

The nose exerts respiratory and olfactory function and is also involved in taste through the nasopharynx connecting the mouth. The nasal cavity is structured in highly vascularized cartilaginous turbinates covered by respiratory epithelium rostrally and olfactory epithelium (OE) dorso-posteriorly (Fig. 2). The contraction of the turbinates through the nasal valve increases the airflow pressure facilitating the passage to the lungs, while the cilia serve as a filtering system for air particulates and microbial species. The depletion of respiratory cilia enhances microbial infections, altering inhalation and smell (Cohen, 2006). Odorants reach the olfactory epithelium through the nares or the nasopharynx and get first trapped in the mucus layering this neuroepithelium (Pelosi, 1994). The mucus secretions produced by the interlining Bowman's glands are rich in glycoproteins and contain odorantbinding proteins, growth- and immune- factors supporting the integrity and the odorant response of the olfactory sensory neurons (OSN) (Federico et al., 1999). Furthermore, the mucus creates a barrier to xenobiotics favoring the colonization of resident microbial species, which are involved in OE turnover and the efficiency of the odorant responses (François et al., 2016). Cholinergic and adrenergic efferents innervate the $\mathrm{OE}$ and regulate the secretory activity of Bowman's gland (Zielinski et al., 1989). As one of the first neurotransmission deficits in $\mathrm{AD}$ concerns the adrenergic afferents to the secretory gland (Grudzien et al., 2007), it is expected that mucus alteration may play out early in disease and could explain the discrepant results of an olfactory threshold dysfunction in mild cognitive impairment (MCI) (Kareken et al., 2001; Djordjevic et al., 2008). Nevertheless, to date no investigation of the mucus biological content has been conducted in $\mathrm{AD}$. Whereas, it has been demonstrated that patients with Parkinson's disease (PD) (Friedman et al., 2008) and amyotrophic lateral sclerosis (ALS) display a change in mucus composition (Federico et al., 1999), likely affecting the functional integrity of the OE. 


\begin{tabular}{|c|c|c|c|}
\hline Anatomy & $\begin{array}{l}\text { Neuropathology } \\
\text { Olfactory epithelium: } \\
\beta \text {-Amyloid aggregates } \\
\text { Degeneration of OSN } \\
\text { Occlusion of the foramina } \\
\text { Olfactory bulb: } \\
\text { Reduction in bulb volume } \\
\text { Prominent tauopathy } \\
\text { Diffused } \beta \text {-amyloid aggregates } \\
\text { Increase in DA neurons } \\
\text { Axonal loss in OT } \\
\text { NFTs and core plaques in AON } \\
\text { Olfactory cortices: } \\
\text { Tauopathy in olfactory tuberculum, PC, } \\
\text { AMG, EC } \\
\text { Amyloidosis and atrophy in OFC } \\
\text { Thalamocortical relay: } \\
\text { Thalamic hypometabolism } \\
\text { Degeneration of the medial thalamus }\end{array}$ & $\begin{array}{l}\text { Pathogen: Host } \\
\text { C.Pneumoniae : ApoE } \varepsilon 4 \\
\text { Spirochete } \\
\text { HSV-1 : ApoE } 84 \\
\text { HHV6A } \\
\text { HHV6B } \\
\text { Air Pollutants (PM }{ }_{2.5} \text { and UFPM) } \\
\text { Metals ( Nickel and Vanadium) } \\
\text { Heavy metals (Thallium, Manganese, } \\
\text { Lead) } \\
\text { Trauma : ApoE } \varepsilon 4\end{array}$ & $\begin{array}{l}\text { Deficits in early } \mathrm{AD} \\
\text { Increased odor sensitivity threshold } \\
\text { Impaired odor identification } \\
\text { Reduced odor discrimination } \\
\text { Impaired odor memory recall } \\
\text { Reduced odor-evoked potentials }\end{array}$ \\
\hline
\end{tabular}

Fig. 2. Anatomy and neuropathological processes of the olfactory system in Alzheimer's disease. Gross anatomy of the nose, the olfactory nerve and the olfactory bulb, reported neuropathology, known pathogenic risk factors, genetics of the host (red) and type of deficits manifests in the early phases of AD. $\mathrm{OSN}=$ olfactory sensory neurons, $\mathrm{DA}=$ dopaminergic, $\mathrm{OT}=$ olfactory tract, $\mathrm{PC}=$ piriform cortex, $\mathrm{AMG}=$ amygdala, $\mathrm{EC}=$ entorhinal cortex, $\mathrm{OFC}=$ orbitofrontal cortex, $\mathrm{PM}=$ particulate matter with a diameter below $2.5 \mu \mathrm{m}$ and UFPM $=$ ultrafine particulate matter.

\subsubsection{Olfactory neuroepithelium}

Besides the olfactory sensory neurons projecting to the brain, the $\mathrm{OE}$ receives afferents from the trigeminal nerve and the nervus terminalis (Fuller and Burger, 1990). The nervous efferents and afferents of the OE represent a sink for microbial species that can be propagated to the brain causing a neuroinflammatory response associated with the development of dementia (Fig. 3A) (Fülöp et al., 2018). Interestingly, bacterial and viral species have been found in the entorhinal cortex (EC), which is part of the olfactory circuitry. In the OE, sustentacular cells are intercalated between the OSN forming a protective and supportive apical monolayer with regenerative capacity. Sustentacular cells have glial-like properties and their renewal is promoted by proliferating globose cells progenitors (Chen et al., 2014). Head trauma or viral infection can temporarily induce the proliferation of the basal cells population (globose and horizontal basal cells) warranting reconstitution of the OE after injury. Nevertheless, when the insult is protracted the chronic inflammatory reaction impairs $\mathrm{OE}$ basal proliferative responses and the function of OSN, leading in the worst case to $\mathrm{OE}$ atrophy and anosmia (Choi and Goldstein, 2018). The progressive loss of olfactory function with age-related neurodegeneration has been attributed to the recurrent insults over a lifespan and the progressive decline in proliferative capacity of senescent stem cells, compromising OE integrity (Witt et al., 2009). Each olfactory sensory neuron expresses a specific G-protein-coupled receptor on its apical cilia, embedded in the nasal mucus layer, that traps the odorants and increases its binding to cognate olfactory receptors. Ciliary defects as result of genetic mutations in the Bardet-Biedl syndrome-gene family members (Kulaga et al., 2004; Iannaccone et al., 2005) or the gene Centrosomal protein 290 (McEwen et al., 2007) cause a complete loss of smell. Moreover, long-term exposure to xenobiotics or chemicals can cause a ciliopathy contributing to the decline in smell with aging (Goncalves and Goldstein, 2016). Furthermore, cilia have been implicated in retrograde transport of several virus species (adenovirus, herpesvirus, poliomyelitis, influenza A and rabies) to the brain (Doty, 2008; Mori et al., 2005) and ablation of the OE or olfactory bulb (OB) in experimental monkeys prevents the entry of the poliomyelitis virus in the CNS (Brodie and Elvidge, 1934). The access of virus into the CNS through the olfactory route is supported by several studies in animals using intranasal inoculation of influenza, herpes and Nipah viruses to study their life cycle and develop vaccine carriers (Bodewes et al., 2011; Plourde et al., 2012; Schrauwen et al., 2012; El-Habashi et al., 2010; Munster et al., 2012; Quinn et al., 2011; van Riel et al., 2015). These studies in animal models are corroborated by increasing reports on the herpesviridae load in the brains of demented patients (Haas and Lathe, 2018; Eimer et al., 2018; Itzhaki, 2014). Further, a damaged olfactory epithelium is permissive to entry of bacterial species to the olfactory bulb within hours curtailing any protective inflammatory response from macrophages of the $\mathrm{OE}$ and olfactory ensheathing cells of the olfactory nerve layer (ONL) (Herbert et al., 2012). Further, Amyloid- $\beta$ aggregates have been reported to accumulate in the olfactory mucosa (OM) from MCI patients (Ayala-Grosso et al., 2015) (Fig. 3B), where the formation of Amyloid- $\beta$ peptides may result from the exposure to microbes (Hill and Lukiw, 2015) building an antibacterial biofilm (Spitzer et al., 2016). These aggregation-prone peptides interfere with OE turnover, likely affecting olfactory transmission (Ayala-Grosso et al., 2015).

In humans, there are about 100-200 different G-protein-coupled olfactory receptors, which are considerably lower than the number of encoding genes (500-600). However, different odorants can activate spatially distinct olfactory receptors (ORs) and the combinatorial affinity of odors to their receptors allow humans to discriminate more than 10'000 odors (Purves et al., 2001a). OR transduction efficiency through c-AMP determines odor threshold sensitivity. With aging, OR expression changes (Verbeurgt et al., 2014) and senescent OR have a deteriorated c-AMP signal transduction, which may explain the age-dependent decline in odor threshold (Purves et al., 2001b).

\subsubsection{Olfactory nerve layer}

Each olfactory sensory neuron projects its axons to the olfactory bulb in bundles through the cribriform plate cavities (Fig. 3A). Occlusion of these foramina occurs naturally with aging and interrupts the olfactory signal transmission from the OSN to the OB affecting the sense of smell (Kalmey and Thewissen, 1998). The olfactory sensory nerve terminals project to the glomerular region of the olfactory bulb maintaining a spatial odorant map defined by the odor class specificity (Mori et al., 1999). After axonal resection of the ONL, as in traumatic brain injury (TBI), rewiring between the $\mathrm{OE}$ and the $\mathrm{OB}$ can be only partially re-established, since odorant map specificity is compromised altering the sense of smell in the long-term (Costanzo, 2005).

\subsection{Secondary olfactory area}

\subsubsection{Olfactory bulb}

The olfactory bulb is the rostral enlarged appendix of the olfactory tract (Fig. 3A). Imaging studies report a progressive reduction in $\mathrm{OB}$ 
volume in AD patients from the MCI stage on (Ridha et al., 2008; Thomann et al., 2009) as well in PD subjects (Mueller et al., 2005; Hummel et al., 2010). The change in mass is associated to a gradual tauopathy in this region (Kovacs and Cairns, 1999; Attems and Jellinger, 2006), but a loss in cell density could not be confirmed (Hummel et al., 2010; Gómez-Isla et al., 1997; Kril et al., 2002), suggesting neuronal network breakdown as the main cause for atrophy. At the tip of the olfactory bulb, olfactory sensory neurons and the apical dendrites of mitral cells converge in a synaptic hallow zone called the glomerular region. In histological studies, this area can be localized using the olfactory marker protein filling the glomeruli or HematoxylinEosin staining showing circular disposed cells. Periglomerular GABAergic and DAergic neurons innervate the dense synaptic regions to modulate the strength of the incoming signal and further tune the specificity of the odorant map (Lledo et al., 2004). The fate of the bulbar GABAergic interneurons in humans remains largely unaddressed (Saiz-Sanchez et al., 2016). On the other hand, DAergic periglomerular neurons are increased in number in $\mathrm{AD}, \mathrm{PD}$ and frontotemporal dementia (FTD) (Mundiñano et al., 2011), suggesting a possible excitatory-inhibitory network dysbalance in the pathogenesis of olfactory dysfunction. This hypothesis is further supported by studies showing alteration in cholinergic (Kovacs et al., 1998; Lehéricy et al., 1993; Ruberg et al., 1986; Rudi et al., 2014), serotonergic (Mössner et al., 2000; Yang and Schmitt, 2001) and noradrenergic (Grudzien et al., 2007; German et al., 1992; Weinshenker, 2008; Zarow et al., 2003) innervations to the $\mathrm{OB}$ in $\mathrm{AD}, \mathrm{PD}$ and FTD patients. Those corticofugal fibers from the forebrain (Horizontal limb of the diagonal band of Broca; HDB) and hindbrain nuclei (Locus coeruleus and Raphe Nuclei) typically modulate the excitability of mitral cells through inhibitory potentiation (Nai et al., 2009; Nai et al., 2010). APP/PS1 transgenic mice show locus coeruleus degeneration which aggravates odor discrimination and memory (Rey et al., 2012). Mechanistically, early functional corticofugal denervation depresses mitral cells excitatory tone, which interferes with synaptic transmission and signal transduction efficiency. Aberrant excitatory transmission has been observed in $\mathrm{AD}$ rodent models (Palop et al., 2007) as well as AD patients (Palop and Mucke, 2009; De Simone et al., 2010). In addition, our recent study demonstrates augmented activity-dependent signaling in mitral cells of MCI patients, which then dissipates with the severity of dementia (Bathini et al., 2018). Progressive network breakdown is supported by other studies showing a gradual proteinopathy that evolves early on in the $\mathrm{OB}$ and is mainly characterized by hyperphosphorylated tau neurofibrils and tangles (Bathini et al., 2018; Lachén-Montes et al., 2017). The Amyloid- $\beta$ pathology remains largely diffused at glomerular level (Fig. 3C) (Mundiñano et al., 2011; Bathini et al., 2018) suggesting that intracellular oligomerization may reflect microbial transformation and cell-to-cell transport. Indeed, trans-synaptic propagation of proteotoxic species along the olfactory nerve could accompany and mimic the trajectory of microbial species from the olfactory bulb to central limbic structures as the entorhinal cortex and hippocampus (Rey et al., 2018).

In rodents, granule and periglomerular interneurons are continuously regenerated also in adult life. In humans, neurogenesis in the olfactory bulb remains a matter of debate (Bergmann et al., 2012, 2015) and interneurons of this region have been marginally characterized. Only a couple of reports indicate that somatostatin and secretogogin interneurons decrease in number in the olfactory bulb and tract with the onset of dementia (Saiz-Sanchez et al., 2010; Attems et al., 2012). It is unclear whether other GABAergic populations of Calbindin, Parvalbumin and Calretinin neurons are affected. However, if the vulnerability of these populations is confirmed, the partial shunting of feedback inhibition would result in de-synchronization of mitral cell firing and an olfactory transmission deficit to higher brain areas.

\subsubsection{Olfactory tract}

From the olfactory bulb, mitral cells send their long axonal projection in a bundle forming the olfactory tract (OT) connecting the olfactory bulb to higher olfactory areas (Fig. 3A). Axonal loss as indicated by a $40 \%$ decrease in OT cross sectional areas and $52 \%$ loss in myelinated axons has been previously reported in $\mathrm{AD}$ patients (Davies et al., 1993). The alteration in structural integrity of the OT, was also detected in our study showing an abrupt decrease in neurotic varicosity already in MCI patients (Bathini et al., 2018).

In the olfactory bulb and tract, the anterior olfactory nucleus (AON) is subdivided in pars bulbar (AONb), interpeduncular (AONi), retrobulbar (AONr). Developmentally, those nuclei are extravagination of the olfactory cortex, AONc (pars corticalis), with layered principal and GABAergic neurons and a progressive proteinopathy characterized by abundant neurofibrillary tangles (NFTs) and small core plaques in AD (Kovacs and Cairns, 1999; Bathini et al., 2018; Hyman et al., 1984; Ter Laak et al., 1994). Despite not completely clarified, these intercalating structures receive projections from mitral neurons and function as intermediate signal integrator (Brunjes and Kenerson, 2010). The pronounced proteinopathy in this region suggests that its activity is significantly impaired in the progression of dementia (Fig. 3D).

\subsection{Olfactory cortices}

\subsubsection{Olfactory tuberculum}

The olfactory tract splits at a bifurcation point called the olfactory tubercle which triages the axons directed to the fornix (medial stria) or the piriform cortex, entorhinal cortex and amygdala (lateral stria) (Fig. 3A). With aging, neurofibrillary tangles accumulate in the olfactory tuberculum compromising the long-range olfactory connectivity (Hyman et al., 1984).

\subsubsection{Piriform cortex}

The majority of the lateral olfactory tract axons project to the twolayered piriform cortex (PC) (Fig. 3A), which represent a sensory-associative center, where odor perception is shaped. Removal of the temporal lobe, often occurring in epileptic patients, affects odor perception but not odor threshold (Gottfried, 2010). Odor coding in the piriform cortex is sparse and results from the integration of excitatoryinhibitory circuitry located rostrally (Anterior Piriform cortex; APC) to caudally (Posterior Piriform cortex; PPC). This structural organization determines the spatial and temporal encoding of odors in dispersed rather than discrete ensembles (Rennaker et al., 2007). This organization allows multi-component odors to be sparsened through local feedforward inhibition into a dominant encoding of the most abundant perceived odor (Poo and Isaacson, 2009) and explains why structurally similar odors are often perceived as different based on the discrete neuronal ensemble recruited in the PC (Gottfried, 2010). Further, a pioneering functional magnetic resonance imaging (fMRI) cross-adaptation study, indicates that the function of the piriform cortex is spatially dissociated in a structure-encoding area (APC) and quality-encoding area (PPC) (Gottfried et al., 2006). MCI patients are unable to qualitatively and categorically distinguish odors during odor identification and discrimination tasks as a result of a disorganization of quality-coding signal strength after repetitive stimuli (Li et al., 2010a). Sensory perception interference may be attributed by different pathophysiological mechanisms ongoing in this region i) the synaptic loss (Arendt, 2009; Giannakopoulos et al., 2009), ii) the observed changes in GABAergic population distribution (decreasing number of calretinin and somatostatin neurons in contrast to increasing parvalbumin cells) and iii) associated tau and Amyloid- $\beta$ pathology evident with the progression of dementia (Fig. 3E) (Saiz-Sanchez et al., 2015). Interestingly, in the Tg2576 animal model of AD, while odor memory is impaired, odor perception is spared suggesting that higher order quality discrimination in human may be more susceptible to early network changes independently of the proteinopathy (Xu et al., 2014). Along these lines, treatment with scopolamine in rats reduces olfactory perceptual memory (Wilson, 2001), suggesting that in humans early perturbations of cholinergic innervation to the piriform cortex could result 
in an odor perception deficit (Geula and Mesulam, 1996). From the PC, monosynaptic afferents reach the orbitofrontal cortex (OFC), which is involved in odor discrimination learning/recognition and multisensory integration (Gottfried, 2010). An older report described a generalized damage and tau pathology in the OFC of $\mathrm{AD}$ patients (Van Hoesen et al., 2000). A spatial topography study confirmed that the OFC undergoes aging-related atrophy (Bakkour et al., 2013), confirming aging as a critical factor in functional olfactory deterioration (Doty and Kamath, 2014).

\subsubsection{Amygdala}

The bypass lateral olfactory tract (LOT) axons further project to the amygdala (AMG) (Fig. 3A). Regional cerebral blood flow PET study in humans indicated that the AMG is recruited bilaterally at exposure of highly aversive stimuli, along with the OFC (Zald and Pardo, 1997). The activity in the AMG is associated with emotional processing of perceived aversiveness of odors, which is in line with the involvement of this limbic structure in negative emotional processing (Halgren, 1982). Neuropathological examination has shown a pronounced tauopathy and cell loss in the AMG with AD progression (Arriagada et al., 1992; Scott et al., 1992; Vereecken et al., 1994). A more recent neuroimaging study indicated that AMG atrophy is prominent in early $\mathrm{AD}$ and relates to the severity of the symptoms (Poulin et al., 2011). The loss in cell mass profoundly compromises olfactory nociception triggering a typical flight response and puts these individuals at risk of exposure to household toxic volatile substances as $\mathrm{CO} 2$ and fire.

\subsubsection{Entorhinal cortex}

The most posterior monosynaptic connections of the LOT end in the entorhinal cortex (EC) (Fig. 3A), organized in 6 cortical layers. Studies in guinea pigs using peristimulus responses indicate that the lateral EC is the target of olfactory inputs from the LOT and associative afferents from the piriform cortex, whereas the medial entorhinal cortex is innervated by hippocampal relay fibers (Biella and de Curtis, 2000). In humans this connectivity is conserved with bidirectional afferents (layer I/II) and efferents (layer II/III) from and to the OB, the PC, the AMG and hippocampus (Cleland and Linster, 2003). The EC mediates odor discrimination memory, as demonstrated by alteration in olfactory recognition in animals with aspiration lesion in this area (Stäubli et al., 1984; Wirth et al., 1998). Further, inhibitory projections from the entorhinal cortex to the piriform cortex contribute to the top-down phasic inhibition and tuning of the piriform cortex resulting in fine odor discrimination ability of similar but not distinct odors (Chapuis et al., 2013), which is a trait affected early on in AD. This is consistent with the stereotypical, layer II (Stranahan and Mattson, 2010), tauopathy with the progression of $\mathrm{AD}$, which is evident already at Braak stage II (Braak et al., 2006; Braak and Del Tredici, 2015). Amyloid- $\beta$ depositions remain scant in the human EC (Braak and Braak, 1991a) suggesting that other mechanisms contribute to the fine odor discrimination deficit in the early stages of AD (Wilson et al., 2014). That said, olfactory discrimination and identification, which depends on the integrity of the PC to EC and OB network remains an important biometric to distinguish normal from pathological brain aging (Murphy, 1999; Bahar-Fuchs et al., 2011; Rahayel et al., 2012). Further, the connectivity of the EC to the hippocampus and AMG explains why odorant exposure may trigger a vivid emotional memory, which is engraved in the subject's history (Mouly and Sullivan, 2011). Besides the long term odor memory, psychophysical testing establishes also the presence of short-term odor memory, as smaller number of odours can be better remembered than a larger panel of odour 2-3 weeks from the first exposure (Schab, 1991). Functional magnetic resonance imaging (fMRI) studies indicate that epileptic patients with temporal lobe lesions show impairment in olfactory memory (Eskenazi et al., 1986). In AD, interference with EC connectivity as a result of the prominent temporal tauopathy impairs odor recognition as evidenced by the investigation of olfactory identification/discrimination in the prediction of dementia
(Devanand et al., 2015).

\subsection{Thalamocortical olfactory relay}

Odors are processed to conscious odor discrimination and memory through bidirectional projections from the olfactory cortices to/from the thalamocortical relay consisting of the medial dorsal thalamus (MDT) and the OFC. These regions are involved in multisensory integration, attention and conscious sensory perception.

\subsubsection{Mediodorsal nucleus of the thalamus}

The MDT receives afferents from the olfactory cortices, the olfactory tubercle and innervates the OFC, while it has feedback connections to the piriform cortex (Fig. 3A). Stimulation of the lateral olfactory tract in animals or the exposure to a variety of odors can induce electrical responses in the MDT in phase with the $\beta$-oscillation of the PC supporting the reciprocal connectivity of these areas (Courtiol and Wilson, 2014). Lesions to the MDT affect odor preference in animals altering sexual behavior (Sapolsky and Eichenbaum, 1980). Similarly in humans, damage to the MDT as a consequence of hemorrhage or ischemia impairs hedonic judgements (Sela et al., 2009). Furthermore, MDT lesions in rats impair olfactory memory and learning (Slotnick and Risser, 1990) and reward association related to odors (Kawagoe et al., 2007) but not visual discrimination, which suggests a specialized function for the MDT in olfactory information coding (Tham et al., 2011a). Based on the role of the thalamus as the gateway of attention, MDT appears to modulate odor attention processing which allows for fine olfactory discrimination and identification of complex mixtures (Tham et al., 2009; Zelano et al., 2011). A study addressing the role of the MDT pathways indicated that patients with MDT lesions perform well in a general olfactory test, but show impairment in olfactory attention and olfactory naming (Tham et al., 2011b). Imaging studies demonstrated that attention to odors increases the functional connectivity of the olfactory cortices-DMT-OFC network (Veldhuizen and Small, 2011; Plailly et al., 2008). These two works support a role of MDT in prediction error signaling where the magnitude of the MDT responses is driven by the expectation of odor stimuli (Zelano et al., 2011). Overall, the studies in animals and humans indicate that MDT executes highorder functions by converting external olfactory stimuli into conscious awareness of odorants through attention. While a variability in neuropathological hallmarks was observed in the MDT of AD patients with a more pronounced tauopathy as compared to senile plaques (Paskavitz et al., 1995; Braak and Braak, 1991b), MRI analysis reveals a robust thalamic degeneration in Alzheimer's patients (Zarei et al., 2010; Vasavada et al., 2017). Morphometry studies indicate that a reduction in thalamic volume is observable already in amnestic MCI (Chételat et al., 2005; Sorg et al., 2007; Yi et al., 2016) and the grade of thalamic shrinkage correlates with the cognitive status (Pedro et al., 2012), suggesting thalamic atrophy as a diagnostic biomarker for conversion from MCI to AD. Furthermore, hypometabolism in the medial thalamus is associated to early decline in executive functions (Reinvang et al., 2012) revealing the relevant connectivity of this region to the frontal cortices. The volumetric changes in the olfactory projection areas support that thalamic relays dysfunction also contributes in the olfactory discrimination and olfactory memory deficit observed in the preclinical phase of $\mathrm{AD}$.

\subsubsection{Orbitofrontal cortex}

The OFC is characterized by 4 broad giri, with reciprocal connections with the olfactory tubercle, the MDT and all primary olfactory areas, including the piriform cortex, amygdala and entorhinal cortex, in the absence of an obligatory thalamic relay (Fig. 3A). Non-overlapping regions of the OFC receive sensory input from gustatory and visual centers, as well as information about visceral states, providing a neural substrate for associative learning and cross-modal integration. In nonhuman primates, the posterior OFC has been identified as the site of 


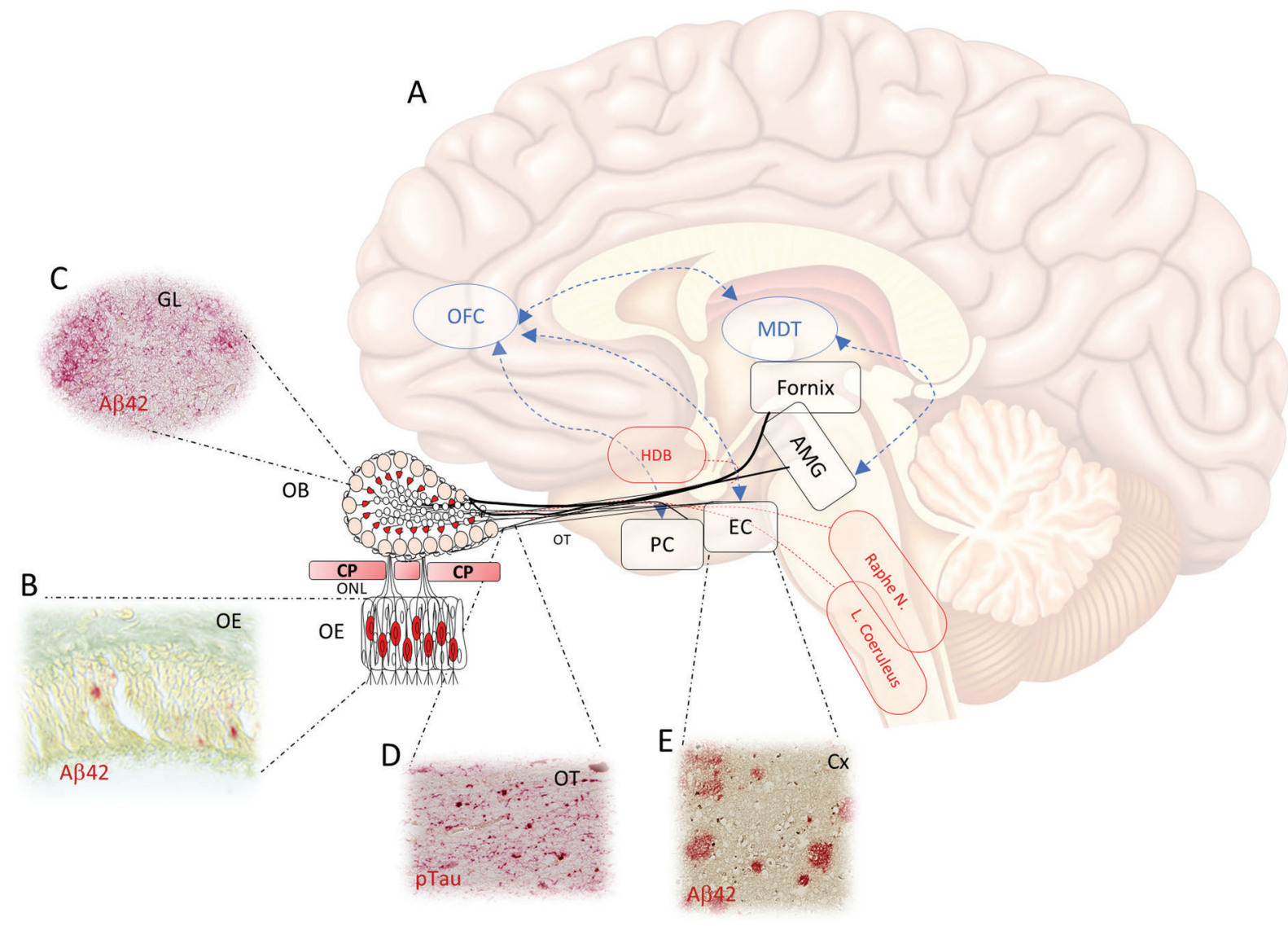

Fig. 3. Olfactory circuitry with typical hallmarks of AD. A) Magnified drawing of the olfactory network superimposed to a half brain hemisphere shows: the peripheral olfactory neuroepithelium in which olfactory sensory neurons (red) are embedded; the olfactory nerve layer projecting to the glomeruli (pink) where synaptic connection with mitral cells (red) are established; mitral cell axons forming the olfactory tract project and bifurcate their monosynaptic terminal either to the fornix or to the olfactory cortices (piriform cortex, entorhinal cortex, amygdala; black). The olfactory cortices are connected viareciprocal connections (dotted blue double arrowed lines) with second order structures (blue), the medial dorsal thalamus and the orbitofrontal cortex; the forebrain nucleus of the Horizontal limb of the diagonal band of Broca and the hindbrain nuclei of the Locus coeruleus and Raphe nucleus send their corticofugal projections to the olfactory bulb. B) A 342 aggregates in the olfactory neuroepithelium. C) A 42 positive diffused plaques in the glomerular region. D) Tauopathy (pTau) in the olfactory tract. E) Core plaques $\mathrm{A} \beta 42$ positive in the entorhinal cortex. $\mathrm{OE}=$ olfactory epithelium, $\mathrm{ONL}=$ olfactory nerve layer, $\mathrm{CP}=$ cribriform plate, $\mathrm{OT}=$ olfactory tract, $\mathrm{OB}=$ olfactory bulb, $\mathrm{GL}=$ glomeruli, $\mathrm{AMG}=$ amygdala, $\mathrm{EC}=$ entorhinal cortex, $\mathrm{PC}=$ piriform cortex, $\mathrm{HDB}=$ Horizontal limb of the diagonal band of Broca, $\mathrm{MDT}=$ medial dorsal thalamus, OFC $=$ orbitofrontal cortex.

olfactory perception (Gottfried, 2006). On the other hand, in humans there is a spatial dissociation between the caudal aspect of the OFC, associated to low-level olfactory processing such as passive smelling and odor detection and its rostral portion devoted to higher order olfactory computation related to associative learning, and odor recognition memory (Gottfried and Zald, 2005). A further topological distinction across the medial lateral axis has been observed in accordance to the pleasantness of the odor with the medial portion of the OFC encoding hedonic odor stimuli and the lateral OFC, unpleasant ones (Gottfried et al., 2002; Anderson et al., 2003; Rolls et al., 2003). The valence-dependent medio-lateral pattern of the OFC is conserved for other sensory modalities (Gottfried, 2006; Small et al., 2001; OöDoherty et al., 2003). The OFC is the primary sensory neo-cortical area, participating in a wide variety of complex olfactory functions related to multimodal integration, reward processing, olfactory consciousness and goal-directed learning and behavior (Gottfried, 2006; Schoenbaum and Eichenbaum, 1995). The OFC has unique role in sensory convergence of odor/taste and odor/vision and semantic correspondence between odors and tastes or between odors and pictures determined also by the anatomical topology (Gottfried, 2006). Orbitofrontal lesions following post-traumatic injury are accompanied by olfactory perception/identification deficits (Jones-Gotman and Zatorre, 1988; Potter and Butters, 1980) underlining the role of the OFC in conscious olfactory experience and multimodal sensory-semantic integration. A more recent work studied an anosmic subject with OFC lesion after TBI using brain imaging, autonomic recordings and olfactory psychophysics and demonstrated that despite the "blind smell" responses registered in the OFC, the subject was completely lacking conscious olfactory perception (Li et al., 2010b). In AD patients, the OFC is characterized by an abundant tauopathy with NFT in layer III and $\mathrm{V}$ containing projection neurons to olfactory cortices (Van Hoesen et al., 2000). The NFT burden correlates with agitation in AD patients (Tekin et al., 2001). More recently, a paper using positron emission tomography (PET) with 11C-pyridinyl-butadienyl-benzothiazole 3 (11C-PBB3) and 11C-Pittsburgh compound-B (11C-PiB), tracers for tau and $A \beta$ respectively, indicated that elevated tau accumulation in the OFC positively correlates with OFC atrophy and apathy scale scores in the patients, while $A \beta$ did not show any significant interaction (Gordon et al., 2018). The sparse Amyloid- $\beta$ pathology in the OFC is confirmed in Tg2576 mice at 16 months (Wesson et al., 2010). Topography crosssectional studies indicate that incipient AD patients show a $20-30 \%$ grey matter loss in the OFC, which becomes less significant with the progression of the disease when temporal atrophy is dominant (Frisoni et al., 2009). This may explain the early sensory deficit observed in the prodromal phase of $\mathrm{AD}$, which is later overruled by the cognitive phenotype at the MCI and moderate stage of AD. While the OFC has been widely studied in FTD for its role on executive function, this area remains less explored in $\mathrm{AD}$ and further investigation is required to 
understand the involvement of the OFC in the early olfactory phenotype.

\subsection{Host-pathogen interactions in the olfactory route}

\subsubsection{The olfactory vector hypothesis in neurodegenerative diseases}

Based on the well documented early olfactory deficit in a variety of neurodegenerative diseases and the accessibility of the olfactory system to the external environment and exogenous species, an olfactory vector hypothesis has been put forward since more than two decades. Environmental factors such as bacteria, viruses, toxins can enter through the airways and disseminate to the brain in the absence of a $\mathrm{BBB}$ and also through the subarachnoid space which expands into the nasal cavity. Microbial species, such as Herpes viridae (Itzhaki et al., 1997; Jamieson et al., 1991), Spirochete (Miklossy, 2008a; Miklossy et al., 1994), and Chlamydiaspecies (Balin et al., 1998), have been found in the olfactory nerve and connected limbic structures suggesting that those species infecting the respiratory tract can enter the brain through the nasal cavity, triggering neuroinflammation and inducing the production and seeding of Amyloid- $\beta$ species for microbicidal purposes (Eimer et al., 2018; Miklossy, 2016). A continuously expanding literature shows that viruses and bacteria inoculated through the nose in rodents can upregulate $A \beta$ processing/deposition (Eimer et al., 2018; Wozniak et al., 2007; Moir et al., 2018; Wozniak et al., 2009; Yount et al., 2006; Little et al., 2004, 2014) through upregulation of $\beta$-secretase and nicastrin (a protein component of the $\gamma$-secretase complex) (Wozniak et al., 2011) and/or via interfering with $A \beta$ intracellular trafficking and clearance (Cheng et al., 2011; Shipley et al., 2005). In $\mathrm{AD}$ patients, the diffused $\mathrm{A} \beta$ pathology in the glomerular region possibly results from microbial infection spreading inter-neuronally through the ONL to the glomeruli (Bathini et al., 2018). Amyloid- $\beta$ peptides have agglutinating properties forming a microbicidal trap likely and limiting the pathogen's dissemination ability (Spitzer et al., 2016; Kumar et al., 2016). On the other hand, a recent contrasting study has advanced that fibrillar $\mathrm{A} \beta$ covering the viral corona increase the infectivity of the pathogen to the brain (Ezzat et al., 2019). While these latter results await confirmation, the overall consensus is that fibrillary $\mathrm{A} \beta$ represents the first innate response to viral and bacterial infection exerting a double sword effect in protection from microbes at the expense of neuronal damage. In addition, microbes in the brain can induce pro-inflammatory reactions with the release of interleukins (IL$1 \beta$, IL-6, IL-8) and tumor necrosis factor- $\alpha$ (TNF- $\alpha$ ) (Lokensgard et al., 2001), which further contribute to neural network breakdown also supported by the prominent and progressive tau pathology with AD.

\subsubsection{Herpesviridae}

In contrast to the punctual host-invasions of bacterial species, Herpesviridae infections are life long and represent one of the most common infectious diseases, with $90 \%$ of the adult population positive for HHV-6 antigens and 60\% for HSV-1 and HSV-2. The latter reside in the body in a latent phase with herpetic outbreaks in $25-40 \%$ of the cases suggesting intraindividual immunological variability. After the first colonization, HSV-1 remains in a latent form in the sensory ganglia, with outburst in condition of stress or immune repression (Itzhaki and Wozniak, 2008). Herpesviridae infections are associated with the production of Amyloid- $\beta$ species that mediate antimicrobial activity through the binding of viral glycoproteins expressed on the surface of infected neurons in vitro (Eimer et al., 2018). This innate immune response explains how viral-induced $\beta$-amyloidosis exacerbate the neurotoxicity following infection. Interestingly, ApoE 4 is positively associated with HSV-1 infections and cold sores in humans (Itzhaki et al., 1997) and ApoE\&4 carriers have increased cerebral load of HSV-1 (Burgos et al., 2006) with a greater risk for females than males mice (Guzman-Sanchez et al., 2012). These data, in addition to the evidence that $A p o E \varepsilon 4$ accelerate early seeding of $A \beta$ (Liu et al., 2017), support a functional interaction between $\mathrm{ApoE} \varepsilon 4$ and the innate immune reaction to viral infections. Microbial traces in the brain of elderly $\mathrm{AD}$ patients emphasize that these species are kept under immunological control until senescence when HSV-1 reactivation from latency is accompanied by upregulation of neuroinflammatory (toll-like receptor-4, interferon $\alpha / \beta$, and p-IRF3) and early neurodegenerative markers (phospho-tau and TauC3) (Martin et al., 2014). A recent study integrating genomic, transcriptomic, proteomic and histopathological data indicated a functional interaction between the presence of HSV-1, HSV-2, HHV-6A and HHV-7 in the prefrontal cortex and hippocampal regions and the incidence of dementia (Jamieson et al., 1991; Readhead et al., 2018). Previously HHV-6A and HHV-6B have been shown to have a tropism for astrocytes in vitro with lytic and nonlytic activity for the two viruses respectively (Donati et al., 2005). When marmoset were intranasally inoculated with both strains, traces of HHV-6B, but not HHV-6A were observed in saliva, blood and in the frontal cortex/olfactory bulb and hippocampus, causing local neuroinflammation and experimental autoimmune encephalomyelitis (Leibovitch et al., 2018). From autopsy brains, HHV-6 shows preferential tropism for the bulb/ tract and both HHV-6B and HHV-6A are generally found in the nasal mucus and saliva from healthy individuals, patients with multiple sclerosis and anosmic subjects (Harberts et al., 2011), independently of the neurological condition. To validate the olfactory route hypothesis of CNS invasion, the same group has confirmed the astrogliosis tropism by infecting with HHV-6A and HHV-6B primary human olfactory ensheathing cells (OEC) typically surrounding the ONL. HHV-6A but not HHV6-B could productively infect the OEC and cause an inflammatory response. Despite the discrepancy of findings between the animal and human specimen, the presence of HHV-6A or HHV-6B in the olfactory system is well documented, whereas it remains to be established whether one or both strains are causative for olfactory-mediated pathogenesis of $\mathrm{AD}$.

\subsubsection{Chlamydia pneumoniae}

Among the airways bacterial species, Chlamydiapneumoniae (C. Pneumoniae), has been found in $90 \%$ of AD brains while only $5 \%$ of the control brains were tested positive. C. Pneumoniae attaches to the nasal epithelium and neuroepithelium and can spread to the brain through the OB, where bacterial traces were found (Balin et al., 1998). To confirm the intranasal spread of the airborne $C$. Pneumoniae to the brain, a study showed the presence of $C$. Pneumoniae antigens along with Amyloid- $\beta$ plaques and astrogliosis in the brain of Balb/c mice, 6 months after intranasal infection (Little et al., 2004, 2014). As for HSV1 , the load of $C$. Pneumoniae in the Alzheimer's brain varies with APOE genotype with ApoEe4 carriers showing higher copy numbers of $C$. Pneumoniae as compared to subjects lacking the risk variant (Gérard et al., 2005). Chlamydial LPS and other membrane proteins induce the secretion of proinflammatory cytokines (IL-6 and MCP-1) and reactive oxygen species from astrocytes with neurotoxic activity (Boelen et al., 2007).

\subsubsection{Spirochete}

Spirochetes, such as Borrelia Burgdorferi (B. burgdorferi) and Treponema denticola, cause latent or persistent infection throughout life (Miklossy, 2008b). With characteristic neurotropism, they can spread to the brain through the blood, lymphatic system and peripheral as well as central nerves including the olfactory tract (Mann et al., 1988; Miklossy, 2011). A meta-analysis has indicated an odd ratio between $100-300 \%$ of identifying one or more species of spirochetes in $A D$ brains or CSF as compared to controls (Miklossy, 2011). B. Burgdorferi was cultivated from postmortem brain of $\mathrm{AD}$ patients (MacDonald and Miranda, 1987) and DNA traces were detected both in brains, blood serum and CSF of AD patients (D'Aniello et al., 1992; Miklossy et al., 1996; Miklossy and Martins, 2008; Miklossy et al., 2004). B. Burgdorferi antigens were associated to neuritic plaques, which are typically more abundant in the olfactory tract, and appear to trigger amyloidogenesis and neuroinflammation (Miklossy, 2008a). In Lyme disease, $B$. 
burgdorferi frequently co-infects with other pathogens, e.g. C. Pneumoniae (Nicolson, 2008) and Herpes viruses (Gylfe et al., 2002). Spirochetes and their surface lipoproteins activate Toll-like Receptor (TLR) signaling through CD14 in macrophages and brain microglia (Sellati et al., 1998) triggering an innate immunity reaction, inducing the bacteriolysis and removal of affected cells but also causing the breakdown of neuronal network integrity.

\subsubsection{Other bacterial species}

A recent report linking dysbiosis in bacterial taxa Moraxella \& Staphylococcus in PD patients and reduced olfactory function further supports the olfactory vector hypothesis in neurodegenerative dementia (Koskinen et al., 2018). One alternative possibility, which might explain the presence of resident microorganisms could be related to the maternal transmission during pre- and post- natal life (Dominguez-Bello et al., 2010). A more recent article, has found that nasal microbial signatures can differentiate between normosmic and hyposmic individuals showing that the microbiome composition of the nasal cavity has a profound effect on olfactory functions (Koskinen et al., 2018). Furthermore, the olfactory route was also successfully employed to deliver the bacteriophage M13, encoding an antibody for $A \beta$, in the $O B$ and hippocampus (Frenkel and Solomon, 2002), confirming the olfactory vector hypothesis.

The bacterial and viral infection are presumably recurrent over a lifetime, however studies indicate that the viral infectious burden correlates better with cognitive decline than the bacterial burden alone (Strandberg et al., 2003). Furthermore, viral and bacterial interactions have been extensively reported in the upper respiratory tract triggering a synergistic action for neuroinflammatory responses and brain colonization (AATM et al., 2013). The clinical relevance of these findings is further corroborated by recent studies showing that antiviral therapy can reduce $A \beta$ and phospho-tau accumulation (Wozniak et al., 2011; Wozniak and Itzhaki, 2013) and that antiherpetic medications reduce the risk of dementia in patients with HSV infections by $90.8 \%$ (Tzeng et al., 2018). That said, careful work from the Itzhaki group indicated that microbial species can be also found in aging healthy individuals (Jamieson et al., 1991), suggesting that pathogen-host interactions are instrumental for the deleterious effects of HSV-1 infection. A more recent GWAS study has found several variants associated with increased herpesviridae infections, however the investigation used a top down multiscale approach to find viral network driver in different existing study cohorts, without parallelization (Readhead et al., 2018). The existing data suggest that microbial pathogens may enter through the nasal route to colonize the brain in slow asymptomatic phase of dementia. Nevertheless, the colonization of the olfactory neuroepithelium by microorganisms appears to be instrumental for the development and the function of the olfactory circuit as demonstrated by the altered kinetics of odorant responses and odorant signal transduction in germ free mice (François et al., 2016). Other infectious agent besides the respiratory pathogens have been implicated in the etiology of $\mathrm{AD}$ and a recent study has demonstrated that the periodontal pathogen, Porphyromonas Gingivalis ( $P$. Gingivalis), progressively accumulates in the brain of $\mathrm{AD}$ patients and gingipains inhibitor treatment in a mouse model of $\mathrm{AD}$ reduces the spread of $P$. Gingivalis and the associated Amyloid- $\beta$ pathology (Dominy et al., 2019), supporting the use of antibiotics in the prevention of the disease. Finally, fungal infections from Candida species are disseminated across various brain regions in $\mathrm{AD}$ patients, including the entorhinal cortex (Pisa et al., 2015a, b). The presence of more than one fungal species has also been observed in neuritic varicosities, called corpora amylacea, in the insular cortex of demented subjects (Pisa et al., 2018). These large extracellular vesicles, likely used as a disposal system by brain cells, are of synaptic origin and are disseminated in the olfactory tract in the older brains (Bathini et al., 2018). While yet to be demonstrated, the presence of fungal, bacterial or viral species (unpublished report) in corpora amylacea may support the polymicrobial invasion of the brain through the olfactory tract.
According to the host-pathogen etiology of $\mathrm{AD}$, the reported gut microbiota dysbiosis (Vogt et al., 2017) could also trigger peripheral inflammatory processes immunocompromising the host and priming it to secondary infections through the airways. Another body of work indicates that on top of microbial antigens, also reactive endogenous molecules released in response to the pathogens (i.e. Amyloid- $\beta$ ) bind to TLRs on microglia perpetuating the neuroinflammatory response (Heneka et al., 2015). In countertendency to the emerging vector hypothesis, a provocative discussion in the emerging topic session the Alzheimer's Association International Conference in 2019 has put forward that late stage infections in immunosuppressed dying demented patient could represent a major confounder to the presence of microbes in the brains as compared to elderly control, who die mainly of cardiac arrest. Considering this last very pertinent argument against the infectious etiology of $\mathrm{AD}$, and the wealth of data supporting it, more studies are needed to assess which and how microbial communities nesting the brain contribute to the disease progression. Additional endeavors comparable to the recent $P$. gingivalis report along with interventional studies are needed to identify the causal relationship between respiratory pathogens and the genetic-environmental-immunological reservoir of the host determining the conversion from physiological to pathological brain aging.

\subsubsection{Antimicrobial function of proteofibrils}

Recent exciting data in animals and in vitro models of AD indicate that bacteria, viruses and fungi trigger the release of amyloid-species from the host cells, forming an antimicrobial trap (Eimer et al., 2018; Kumar et al., 2016; Soscia et al., 2010). The insoluble Amyloid- $\beta$ peptides form a fibrillary net that confines the pathogens but also trigger neuroinflammation. There are about 100 naturally occurring antimicrobial peptides in humans (LAMP, 2019). In addition, another paper described that $\alpha$-synuclein, which is highly expressed in the olfactory neurons, represents the first line of defense to the invasion of reoviruses inoculated through the nose (Tomlinson et al., 2017). While Amyloid- $\beta$ is prevalently diffused and intracellular in the olfactory bulb, the abundance of $\alpha$-synuclein aggregates throughout the olfactory nerve supports innate immune mechanisms against the entry of pathogens to connected limbic areas.

\subsubsection{Air pollutants}

Air pollution consists of a complex mixture of particulate matter (PM), gases (e.g. ground-level ozone, carbon monoxide, sulfur oxides, nitrogen oxides), organic compounds (e.g. polycyclic aromatic hydrocarbons and endotoxins) and metals (e.g. vanadium, nickel, and manganese) (Akimoto, 2003). Besides the lungs and the blood stream, pollutants present in outdoor and indoor air can enter the brain through the olfactory neuroepithelium (Doty, 2008). Fine particles below $2.5 \mu \mathrm{m}$ of diameter $\left(\mathrm{PM}_{2.5}\right)$ and ultrafine particles (UFPM) of less than $0.1 \mu \mathrm{m}$ of diameter are most common in the urban environment and can cross the mucosal barrier of the lungs and nose gaining access to the peripheral circulation and the brain (Simkhovich et al., 2008). Subjects chronically exposed to air particulates, display OB hyperplasia accompanied by nanoparticles accumulation in neurons and $A \beta$ aggregates (Calderón-Garcidueñas et al., 2010). Feral dogs exposed to high concentration of urban pollution show accumulation of nickel and vanadium traces along the olfactory circuit from the olfactory mucosa to the frontal cortex (Calderon-Garciduenas et al., 2002, 2003). Similarly, heavy metals such as lead, manganese and thallium, which have been associated with an early onset of progressive neurodegenerative disease as AD, PD and ALS, are inhaled through the airways and accumulate in the brain interfering with cellular metabolism, neuronal transmission and inducing cell death (Chen et al., 2016). Studies in humans and animal models confirm that exposure to air pollutants increases the levels of proinflammatory cytokines (Interleukin1- $\beta$, IL1- $\beta$; cyclo-oxygenase 2, COX2), deposition of proteotoxic species (Amyloid- $\beta$ and $\alpha$ synuclein), BBB leakage (Calderón-Garcidueñas et al., 2008a), 
increased microglia activation, infiltrating monocytes as well as prefrontal cortex lesions (Calderón-Garcidueñas et al., 2008b). Young humans and dogs appear particularly vulnerable to the air pollutants causing a life-long inflammatory state and carrying a considerable risk for the development of $\mathrm{AD}$ and $\mathrm{PD}$ with aging. On the other hand, paradoxically, smoking has been inversely correlated with the development of olfactory dysfunctions and cognitive impairment (Hoffman et al., 2016). Finally, exposure to pesticides and herbicides increases the risk of developing AD (Richardson et al., 2014) and PD (Parrón et al., 2011), without significantly affecting olfactory functions (Steenland et al., 2000).

\subsubsection{Head trauma and pathogen entry}

Head trauma represents a significant risk for the development of dementia (Gottlieb, 2000). Even low grade head concussion, mild TBI, can cause hyposmia or in the worst case anosmia in the long term as a result of reduced olfactory bulb volume, lesions in the OFC (Han et al., 2018; Proskynitopoulos et al., 2016), olfactory nerve denervation and/ or degeneration of the olfactory neuroepithelium (Holbrook et al., 2005). The mechanical shearing of the olfactory structures damages their integrity and causes a sustained inflammatory response that may deplete the innate immune reservoir making it more susceptible to pathogen entry and invasion to the brain. In line with the role of ApoE in regulating the efficiency of the immune response, ApoE 44 carriers have poorer long-term outcome after TBI as compared to non-carriers (Ponsford et al., 2011; Nathoo et al., 2003). Even chronic rhinosinusitis (CRS) causes a protracted inflammatory damage (Lane et al., 2010) to the respiratory and olfactory mucosa resulting in chronic hyposmia in $30 \%-70 \%$ of the cases and a potential neuropathological spread to the brain. Hyposmia after head trauma may represent a first sentinel for subsequent conversion to dementia (Hüttenbrink et al., 2013).

\subsection{Olfactory gateway of peripheral to central inflammatory responses}

The absence of a BBB in the olfactory circuitry makes it susceptible for spreading immune reactions from the periphery to the brain. With the protracted exposure to xenobiotics the olfactory neuroepithelium releases Amyloid- $\beta$ peptides, forming a bactericidal trapping biofilm on one side but also affecting OSN integrity triggering local immune process and potentially stimulating the infiltration of innate immune cells to the brain. The local immune reaction in the nasal epithelium in response to microbes was demonstrated by intranasal administration of the viral mimicking molecule Polyinosinic:polycytidylic acid (PolyI:C), which causes a transient invasion of neutrophils, T-cells, monocytes and macrophages, tissue atrophy at 3 days and regeneration at 9 days postinjection (Kanaya et al., 2014). Interestingly, the inflammatory reaction to xenobiotics contributes to the neurogenesis of basal progenitors stem cells through the macrophages-mediated release of TNF- $\alpha$ and nuclear factor kappa-light-chain-enhancer of activated B cells (NFk-B) (Borders et al., 2007; Chen et al., 2017). As for other organs the regenerative capacity of the olfactory neuroepithelium decays with aging both in humans and rodents (Child et al., 2018; Holbrook et al., 2011; Kondo et al., 2010), limiting the neurogenesis-promoting action of the innate immunity, while maintaining the inflammatory effect. This scenario is common in patients with chronic rhinosinusitis with hyposmia or transient anosmia, showing structurally and functionally altered neuroepithelium (Doty and Mishra, 2001). In CRS mouse model, producing a persistent release of TNF- $\alpha$, the integrity of the olfactory epithelium is compromised with evident neuronal loss (Farbman et al., 1999; Suzuki and Farbman, 2000). A more recent report, showed that nasal administration of LPS causes rostral-caudal alterations following the olfactory circuitry trajectory: i) a rapid local increase in IL-1 $\beta$ within 3 days, ii) infiltration of macrophages to the OM with concomitant loss of OSN, iii) degeneration of olfactory sensory axons, astrogliosis in the OB's glomeruli, iv) reduction in the dopaminergic periglomerular neurons, v) a decrease in synapses on mitral/tufted cell dendrites and vi) a decline interneurons of the granular layer (Hasegawa-Ishii et al., 2017). The authors did not explore changes in the olfactory cortical areas but infer alterations in these regions based on the synaptic loss of mitral/tufted neurons, likely affecting their long-range transmission. In humans, CRS has been identified as a putative risk factor for the development of $\mathrm{AD}$ (Yasue et al., 2015). In a population based case-control study of more than 17'000 subjects, prior incidence of CRS has been shown to increase the risk of dementia by $44 \%$ as compared to controls (Chung et al., 2015). Another retrospective study shows that reported allergic rhinitis is positively associated with PD, whereas the use of non-steroidal antiinflammatory drugs (NSAID) is negatively linked to PD onset. The study suffers from the referral bias from the sampled population and the lack of phenotype classification but provides an additional piece of evidence that chronic inflammation in response to infection may underlie the development of PD (Bower et al., 2006). Taken the emergent role of ApoE (Zhang et al., 2011; Gonzalez et al., 2017), clusterin (CLU) (Falgarone and Chiocchia, 2009; Hong et al., 2016), triggering receptor expressed on myeloid cells 2 (TREM2) in innate immunity (Fahrenhold et al., 2018; Jay et al., 2015; Shi and Holtzman, 2018), and their convergence as risk variants for sporadic $\mathrm{AD}$, it is likely that an altered inflammatory response to exogenous substances in the airways is transferred through the olfactory neuroepithelium to the connected olfactory circuitry. This is supported by the increased infections incidence of viruses in ApoEs4 carriers (HSV-1, HIV1, Hepatitis C, Hepatitis B) (Itzhaki et al., 1997; Burgos et al., 2006; Finch and Morgan, 2007; Burt et al., 2008; Hishiki et al., 2010; Yin et al., 2010) and bacteria (C. Pneumoniae, Gram negative bacteria) (de Bont et al., 1999; Van Oosten et al., 2001; Kattan et al., 2008). Along the same lines, subjects with at least one ApoE\&4 allele display early olfactory identification and olfactory memory deficits and have a higher risk to convert to AD (Murphy et al., 2009; Calhoun-Haney and Murphy, 2005; Gilbert and Murphy, 2004; Bacon et al., 1998). ApoE suppresses inflammation through its binding to the very low density lipoprotein receptor (VLDLR) and apolipoprotein receptor 2 (ApoER2) receptors in macrophages (Baitsch et al., 2011) and by inhibiting the complement cascade (Yin et al., 2019). As macrophages influence the regeneration of the olfactory epithelium after mechanical injury or infection, it is possible that the effect of ApoE on the turnover of the olfactory epithelium (Nathan et al., 2007, 2005; Hussain et al., 2013) and OSN transduction (Wetter and Murphy, 2001; Covington et al., 1999) is directly mediated by the immunogenic phenotype of macrophages. Accordingly, anosmia in MCI and AD patients is concurrent to the frequency of ApoEs4 allele and the signs of inflammation in the OM (Ayala-Grosso et al., 2015). Despite this evidence, more studies are needed to address whether the olfactory deficit observed in ApoE 44 results from an early inflammatory imbalance anticipating an olfactory neuropathological spread. In additional support to the transfer of peripheral immune cells centrally, a more permeable/disrupted BBB or a dystrophic neuroepithelium as a result of aging, chronic inflammation or TBI allows the infiltration of monocytes, T- and B-cells to the brain (Prinz and Priller, 2017; Cross et al., 2013). A chronic low inflammatory grade, as with airways infections, can create the premises for the xenobiotic spread triggering the production of anti-microbial amyloids and an abnormal neuroinflammatory response underlying the progressive pathogenesis of $\mathrm{AD}$ (Mori et al., 2005; Gillet et al., 2015).

\subsection{Olfactory biomarkers in $A D$}

Olfaction can be tested routinely using inexpensive self-administrable odor threshold, odor identification/discrimination and odor memory tests. Few studies with different olfactory tests assessing the relationship between olfactory function and its association with cognitive decline are listed in Table 1.

Odor threshold is considered a purely olfactory activity indicator, depending on the integrity of the olfactory neuroepithelium and OSN transduction. Changes in the odor threshold are usually detected using 
a T\&T olfactometer and olfactory perception threshold test kits like Olfactolab No.11 (Saiki et al., 1994; Fortier et al., 1991). The test requires repetitive trials with defined intervals between exposures to the odors.

Olfactory identification pertains the detection of odors based on an historic repertoire of previously smelled odors, it engages both peripheral and central olfactory areas. Olfactory discrimination requires both memory of previous odors as well as intact executive verbal functions allowing to differentiate between 2 or more odorants, it involves mainly olfactory cortical areas.

Finally, olfactory memory is one of the most engrained formed of memory and entails the recall of a situation, image, name based on the smelled odor. It depends on the transmission of the olfactory signal to the hippocampus and the retrieval of context-dependent memories. In other studies using psychophysical tests, olfactory event-related potentials and functional imaging, olfactory impairment served as a differentiating factor to detect early AD (Peters et al., 2003; Förster et al., 2010).

Olfactory alteration in late phases of dementia is characterized by a marked increase in olfactory threshold levels (Doty et al., 1987) and a decreased smell recognition profile in $\mathrm{AD}$ patients (Knupfer and Spiegel, 1986). Olfactory identification tests are the most commonly employed and olfactory identification deficits in elderly individuals can diagnose the conversion to dementia in a 3 years period (Devanand et al., 2008). As chemosensory impairment is not limited to olfaction alone, in a multiple chemosensory task, Koss et al. studied both olfactory identification and taste detection in patients with mild symptoms of $\mathrm{AD}$. In contrast to unaltered odor detection and taste detection thresholds, subjects with mild AD scored worse in olfactory identification task following trigeminal stimulation, suggesting that the chemosensory impairment in $\mathrm{AD}$ is central rather than peripheral (Koss et al., 1988). PET studies showed that olfactory and visual discrimination deteriorate with severity of dementia. In the olfactory discrimination task, $\mathrm{AD}$ patients show severe impairment and that the differences between mild and moderated AD are very subtle but in the visual discrimination task subjects with mild $\mathrm{AD}$ symptoms performed better than the moderate AD ones (Elisabeth, 1986). In another multisensory study researchers demonstrated increased olfactory threshold levels in early phases of dementia without any change in their taste threshold (Murphy et al., 1990). Overall, these evidence indicate that chemosensation is ideally suited for early detection and monitoring of $\mathrm{AD}$ onset and progression.

\section{Conclusions}

Chemosensory functions decline with aging, therefore affecting the abilities of elderly people and impacting on their quality of life. Smell loss is further aggravated in dementia and in some cases precedes the onset of cognitive decline. Chemosensory deficit is an overarching condition, lacking specificity for one type of dementia, and as such its diagnostic power has been underestimated. However, sensory biometrics represent an opportunity to study common mechanisms in neurodegenerative diseases both at network as well as molecular level. In light of the recent studies corroborating the viral hypothesis of dementia, and the causal link between infection and amyloidogenesis, the sensory peripheral organs devoid of blood brain barrier, such as the olfactory circuitry, assume particular clinical relevance for a neuroinflammatory spreading that can underlie the slow and progressive rostral to caudal neurodegeneration in AD. On the other hand, there is an increasing interest in exploiting the accessibility of the olfactory nerve for biomarker discovery and there is a concrete potential for using the combination of multiple sensory modalities to improve the early diagnostic of $\mathrm{AD}$. This review has attempted to collect the most up to date literature and we realize that while the functional anatomy of the chemosensory circuit is well characterized, host-pathogenic interactions are just beginning to emerge. If host-pathogen mechanisms of 
early sensory dysfunctions are identified as culprit of neurodegenerative progression, early non-invasive sensory diagnostics could pave the way to timely and targeted therapeutics adapted to the immunological profile of each subject.

\section{Funding}

This project is supported by funds of the Swiss National Science Foundation (N.163470; LA), the Ministry of Science and Education Switzerland (ESKAS No. 2017.0480; PB) and the Human Brain Project (SP8.7; LA).

\section{Declaration of Competing Interest}

The authors declare that they have no competing interests.

\section{References}

World Alzheimer Reports, 2018. World Alzheimer Reports | Alzheimer's Disease International. [Internet]. 6 Sep [cited 24 Apr 2019]. Available:. . https://www.alz. co.uk/research/WorldAlzheimerReport2018.

Budson, A.E., Solomon, P.R., 2012. New diagnostic criteria for Alzheimer's disease and mild cognitive impairment for the practical neurologist. Pract. Neurol. 12, 88-96.

perling, R.A., Aisen, P.S., Beckett, L.A., Bennett, D.A., Craft, S., Fagan, A.M., et al., 2011. Toward defining the preclinical stages of Alzheimer's disease: recommendations from the National Institute on Aging-Alzheimer's Association workgroups on diagnostic guidelines for Alzheimer's disease. Alzheimers Dement. 7, 280-292.

Arnold, S.E., Lee, E.B., Moberg, P.J., Stutzbach, L., Kazi, H., Han, L.-Y., et al., 2010. Olfactory epithelium amyloid-beta and paired helical filament-tau pathology in Alzheimer disease. Ann. Neurol. 67, 462-469.

Christen-Zaech, S., Kraftsik, R., Pillevuit, O., Kiraly, M., Martins, R., Khalili, K., et al., 2003. Early olfactory involvement in Alzheimer's disease. Can. J. Neurol. Sci. 30, 20-25.

Goldstein, L.E., Muffat, J.A., Cherny, R.A., Moir, R.D., Ericsson, M.H., Huang, X., et al., 2003. Cytosolic $\beta$-amyloid deposition and supranuclear cataracts in lenses from people with Alzheimer's disease. Lancet. 361, 1258-1265.

ewis, D.A., Campbell, M.J., Terry, R.D., Morrison, J.H., 1987. Laminar and regional distributions of neurofibrillary tangles and neuritic plaques in Alzheimer's disease: a quantitative study of visual and auditory cortices. J. Neurosci. 7, 1799-1808.

Itzhaki, R.F., Lathe, R., Balin, B.J., Ball, M.J., Bearer, E.L., Braak, H., et al., 2016. Microbes and alzheimer's disease. J. Alzheimers Dis. 51, 979-984.

Zhang, H., Wu, L.-M., Wu, J., 2011. Cross-talk between apolipoprotein E and cytokines. Mediators Inflamm., 9490722011.

Cohen, N.A., 2006. Sinonasal mucociliary clearance in health and disease. Ann. Otol. Rhinol. Laryngol. Suppl. 196, 20-26.

Pelosi, P., 1994. Odorant-binding proteins. Crit. Rev. Biochem. Mol. Biol. 29, 199-228 Taylor \& Francis.

ederico, G., Maremmani, C., Cinquanta, L., Baroncelli, G.I., Fattori, B., Saggese, G., 1999. Mucus of the human olfactory epithelium contains the insulin-like growth factor-I system which is altered in some neurodegenerative diseases. Brain Res. 835, 306-314.

François, A., Grebert, D., Rhimi, M., Mariadassou, M., Naudon, L., Rabot, S., et al., 2016. Olfactory epithelium changes in germfree mice. Sci. Rep. 6, 24687.

Zielinski, B.S., Getchell, M.L., Wenokur, R.L., Getchell, T.V., 1989. Ultrastructural localization and identification of adrenergic and cholinergic nerve terminals in the olfactory mucosa. Anat. Rec. 225, 232-245.

Grudzien, A., Shaw, P., Weintraub, S., Bigio, E., Mash, D.C., Mesulam, M.M., 2007. Locus coeruleus neurofibrillary degeneration in aging, mild cognitive impairment and early Alzheimer's disease. Neurobiol. Aging 28, 327-335.

Kareken, D.A., Doty, R.L., Moberg, P.J., Mosnik, D., Chen, S.H., Farlow, M.R., et al., 2001. Olfactory-evoked regional cerebral blood flow in Alzheimer's disease. Neuropsychology 15, 18-29.

Djordjevic, J., Jones-Gotman, M., De Sousa, K., Chertkow, H., 2008. Olfaction in patients with mild cognitive impairment and Alzheimer's disease. Neurobiol. Aging 29, 693-706.

Friedman, J.H., Amick, M.M., Chou, K.L., 2008. Rhinorrhea and olfaction in Parkinson disease. Neurology. 70, 487-489.

Fuller, G.N., Burger, P.C., 1990. Nervus terminalis (cranial nerve zero) in the adult human. Clin. Neuropathol. 9, 279-283.

Fülöp, T., Itzhaki, R.F., Balin, B.J., Miklossy, J., Barron, A.E., 2018. Role of microbes in the development of alzheimer's disease: state of the art - an international symposium presented at the 2017 IAGG congress in San Francisco. Front. Genet. 9, 362.

Chen, C.R., Kachramanoglou, C., Li, D., Andrews, P., Choi, D., 2014. Anatomy and cellular constituents of the human olfactory mucosa: a review. J. Neurol. Surg. B Skull Base 75, 293-300.

Choi, R., Goldstein, B.J., 2018. Olfactory epithelium: cells, clinical disorders, and insights from an adult stem cell niche. Laryngoscope Investig. Otolaryngol. 3, 35-42.

Witt, M., Bormann, K., Gudziol, V., Pehlke, K., Barth, K., Minovi, A., et al., 2009. Biopsies of olfactory epithelium in patients with Parkinson's disease. Mov. Disord. 24, 906-914.
Kulaga, H.M., Leitch, C.C., Eichers, E.R., Badano, J.L., Lesemann, A., Hoskins, B.E., et al., 2004. Loss of BBS proteins causes anosmia in humans and defects in olfactory cilia structure and function in the mouse. Nat. Genet. 36, 994-998.

Iannaccone, A., Mykytyn, K., Persico, A.M., Searby, C.C., Baldi, A., Jablonski, M.M., et al., 2005. Clinical evidence of decreased olfaction in Bardet-Biedl syndrome caused by a deletion in the BBS4 gene. Am. J. Med. Genet. A 132, 343-346 Wiley Online Library.

McEwen, D.P., Koenekoop, R.K., Khanna, H., Jenkins, P.M., Lopez, I., Swaroop, A., et al, 2007. Hypomorphic CEP290/NPHP6 mutations result in anosmia caused by the selective loss of $\mathrm{G}$ proteins in cilia of olfactory sensory neurons. Proc. Natl. Acad Sci. U. S. A. 104, 15917-15922.

Goncalves, S., Goldstein, B.J., 2016. Pathophysiology of Olfactory Disorders and Potential Treatment Strategies. Curr. Otorhinolaryngol. Rep. 4, 115-121.

Doty, R.L., 2008. The olfactory vector hypothesis of neurodegenerative disease: is it viable? Ann. Neurol. 63, 7-15.

Mori, I., Nishiyama, Y., Yokochi, T., Kimura, Y., 2005. Olfactory transmission of neurotropic viruses. J. Neurovirol. 11, 129-137.

Brodie, M., Elvidge, A.R., 1934. The portal of entry and transmission of the virus of poliomyelitis. Sci. Am. Assoc. Adv. Sci. 79, 235-236.

Bodewes, R., JHCM, K., van Amerongen, G., Fouchier, R.A.M., ADME, O., Rimmelzwaan, G.F., et al., 2011. Pathogenesis of Influenza A/H5N1 virus infection in ferrets differs between intranasal and intratracheal routes of inoculation. Am. J. Pathol. 179, $30-36$.

Plourde, J.R., Pyles, J.A., Layton, R.C., Vaughan, S.E., Tipper, J.L., Harrod, K.S., 2012. Neurovirulence of H5N1 infection in ferrets is mediated by multifocal replication in distinct permissive neuronal cell regions. PLoS One 7, e46605.

Schrauwen, E.J.A., Herfst, S., Leijten, L.M., van Run, P., Bestebroer, T.M., Linster, M., et al., 2012. The multibasic cleavage site in H5N1 virus is critical for systemic spread along the olfactory and hematogenous routes in ferrets. J. Virol. 86, 3975-3984.

El-Habashi, N., El-Nahass, E.-S., Fukushi, H., Hibi, D., Sakai, H., Sasseville, V., et al., 2010. Experimental intranasal infection of equine herpesvirus 9 (EHV-9) in suckling hamsters: kinetics of viral transmission and inflammation in the nasal cavity and brain. J. Neurovirol. 16, 242-248.

Munster, V.J., Prescott, J.B., Bushmaker, T., Long, D., Rosenke, R., Thomas, T., et al., 2012. Rapid Nipah virus entry into the central nervous system of hamsters via the olfactory route. Sci. Rep. 2, 736 .

Quinn, K., Quirion, M.R., Lo, C.-Y., Misplon, J.A., Epstein, S.L., Chiorini, J.A., 2011. Intranasal administration of adeno-associated virus type 12 (AAV12) leads to transduction of the nasal epithelia and can initiate transgene-specific immune response. Mol. Ther. 19, 1990-1998.

van Riel, D., Verdijk, R., Kuiken, T., 2015. The olfactory nerve: a shortcut for influenza and other viral diseases into the central nervous system. J. Pathol. 235, 277-287.

Haas, J.G., Lathe, R., 2018. Microbes and Alzheimer's Disease: new findings call for a paradigm change. Trends Neurosci. 41, 570-573.

Eimer, W.A., Vijaya Kumar, D.K., Navalpur Shanmugam, N.K., Rodriguez, A.S., Mitchell, T., Washicosky, K.J., et al., 2018. Alzheimer's disease-associated B-Amyloid is rapidly seeded by herpesviridae to protect against brain infection. Neuron 99, 56-63 e3.

Itzhaki, R.F., 2014. Herpes simplex virus type 1 and Alzheimer's disease: increasing evidence for a major role of the virus. Front. Aging Neurosci. 6, 202.

Herbert, R.P., Harris, J., Chong, K.P., Chapman, J., West, A.K., Chuah, M.I., 2012. Cytokines and olfactory bulb microglia in response to bacterial challenge in the compromised primary olfactory pathway. J. Neuroinflammation 9, 109.

Ayala-Grosso, C.A., Pieruzzini, R., Diaz-Solano, D., Wittig, O., Abrante, L., Vargas, L., et al., 2015. Amyloid-a $\beta$ peptide in olfactory mucosa and mesenchymal stromal cells of mild cognitive impairment and alzheimer's disease patients: amyloid in olfactory mucosa of alzheimer disease. Brain Pathol. 25, 136-145.

Hill, J.M., Lukiw, W.J., 2015. Microbial-generated amyloids and Alzheimer's disease (AD). Front. Aging Neurosci. 7, 9.

Spitzer, P., Condic, M., Herrmann, M., Oberstein, T.J., Scharin-Mehlmann, M., Gilbert, D.F., et al., 2016. Amyloidogenic amyloid- $\beta$-peptide variants induce microbial agglutination and exert antimicrobial activity. Sci. Rep. 6, 32228.

Purves, D., Augustine, G.J., Fitzpatrick, D., Katz, L.C., LaMantia, A.-S., McNamara, J.O. et al., 2001a. Odorant Receptors and Olfactory Coding. Sinauer Associates.

Verbeurgt, C., Wilkin, F., Tarabichi, M., Gregoire, F., Dumont, J.E., Chatelain, P., 2014 Profiling of olfactory receptor gene expression in whole human olfactory mucosa. PLoS One 9, e96333.

Purves, D., Augustine, G.J., Fitzpatrick, D., Katz, L.C., LaMantia, A.-S., McNamara, J.O., et al., 2001b. The Transduction of Olfactory Signals. Sinauer Associates.

Kalmey, J.K., Thewissen, J.G.M., 1998. Age-related Size Reduction of Foramina in the Cribriform Plate. Anat Rec. Wiley Online Libraryhttps://doi.org/10.1002/(SICI) 1097-0185(199807)251:3\%3C326::AID-AR7\%3E3.0.CO;2-T. Available:

Mori, K., Nagao, H., Yoshihara, Y., 1999. The olfactory bulb: coding and processing of odor molecule information. Science 286, 711-715.

Costanzo, R.M., 2005. Regeneration and rewiring the olfactory bulb. Chem. Senses 30 (Suppl 1), i133-4.

Ridha, B.H., Anderson, V.M., Barnes, J., Boyes, R.G., Price, S.L., Rossor, M.N., et al., 2008 Volumetric MRI and cognitive measures in Alzheimer disease: comparison of markers of progression. J. Neurol. 255, 567-574.

Thomann, P.A., Dos Santos, V., Seidl, U., Toro, P., Essig, M., Schröder, J., 2009. MRIderived atrophy of the olfactory bulb and tract in mild cognitive impairment and Alzheimer's disease. J. Alzheimers Dis. 17, 213-221.

Mueller, A., Abolmaali, N.D., Hakimi, A.R., Gloeckler, T., Herting, B., Reichmann, H., et al., 2005. Olfactory bulb volumes in patients with idiopathic Parkinson's disease a pilot study. J. Neural Transm. 112, 1363-1370.

Hummel, T., Witt, M., Reichmann, H., Welge-Luessen, A., Haehner, A., 2010. Immunohistochemical, volumetric, and functional neuroimaging studies in patients with idiopathic Parkinson's disease. J. Neurol. Sci. 289, 119-122. 
Kovacs, T., Cairns, N.J., 1999. Lantos PL. Beta-amyloid deposition and neurofibrillary tangle formation in the olfactory bulb in ageing and Alzheimer's disease. Neuropathol. Appl. Neurobiol. 25, 481-491.

Attems, J., Jellinger, K.A., 2006. Olfactory tau pathology in Alzheimer disease and mild cognitive impairment. Clin. Neuropathol. 25, 265-271.

Gómez-Isla, T., Hollister, R., West, H., Mui, S., Growdon, J.H., Petersen, R.C., et al., 1997. Neuronal loss correlates with but exceeds neurofibrillary tangles in Alzheimer's disease. Ann. Neurol. 41, 17-24.

Kril, J.J., Patel, S., Harding, A.J., Halliday, G.M., 2002. Neuron loss from the hippocampus of Alzheimer's disease exceeds extracellular neurofibrillary tangle formation. Acta Neuropathol. 103, 370-376.

Lledo, P.-M., Saghatelyan, A., Lemasson, M., 2004. Inhibitory interneurons in the olfactory bulb: from development to function. Neuroscientist. 10, 292-303.

Saiz-Sanchez, D., Flores-Cuadrado, A., Ubeda-Bañon, I., de la Rosa-Prieto, C., MartinezMarcos, A., 2016. Interneurons in the human olfactory system in Alzheimer's disease. Exp. Neurol. 276, 13-21.

Mundiñano, I.-C., Caballero, M.-C., Ordóñez, C., Hernandez, M., DiCaudo, C., Marcilla, I., et al., 2011. Increased dopaminergic cells and protein aggregates in the olfactory bulb of patients with neurodegenerative disorders. Acta Neuropathol. 122, 61-74.

Torok, I., Kovacs, I., Zombori, J., Kasa, P., 1998. Cholinergic structures and neuropathologic alterations in the olfactory bulb of Alzheimer's disease brain samples. Brain Res. 789, 167-170.

Lehéricy, S., Hirsch, E.C., Cervera-Piérot, P., Hersh, L.B., Bakchine, S., Piette, F., et al., 1993. Heterogeneity and selectivity of the degeneration of cholinergic neurons in the basal forebrain of patients with Alzheimer's disease. J. Comp. Neurol. 330, 15-31.

Ruberg, M., Rieger, F., Villageois, A., Bonnet, A.M., Agid, Y., 1986. Acetylcholinesterase and butyrylcholinesterase in frontal cortex and cerebrospinal fluid of demented and non-demented patients with Parkinson's disease. Brain Res. 362, 83-91.

Rudi, A.J., Otte, A., de Vries, E.F.J., van Waarde, A., Leenders, K.L., 2014. PET and SPECT in Neurology. Springer.

Mössner, R., Schmitt, A., Syagailo, Y., Gerlach, M., Riederer, P., Lesch, K.P., 2000. The serotonin transporter in Alzheimer's and Parkinson's disease. J. Neural Transm. Suppl. 345-350.

Yang, Y., Schmitt, H.P., 2001. Frontotemporal dementia: evidence for impairment of ascending serotoninergic but not noradrenergic innervation. Acta Neuropathol. 101, 256-270.

erman, D.C., Manaye, K.F., White, C.L.I.I.I., Woodward, D.J., McIntire, D.D., Smith, W.K., et al., 1992. Disease-specific patterns of locus coeruleus cell loss. Ann Neurol. Wiley Online Library 32, 667-676.

Weinshenker, D, 2008. Functional consequences of locus coeruleus degeneration in Alzheimer's disease. Curr. Alzheimer Res. 5, 342-345.

Zarow, C., Lyness, S.A., Mortimer, J.A., Chui, H.C., 2003. Neuronal loss is greater in the locus coeruleus than nucleus basalis and substantia nigra in Alzheimer and Parkinson diseases. Arch. Neurol. 60, 337-341.

Nai, Q., Dong, H.W., Linster, C., Ennis, M. 2010. Activation of alpha1 and alpha2 noradrenergic receptors exert opposing effects on excitability of main olfactory bulb granule cells. Neuroscience. 169, 882-892.

Nai, Q., Dong, H.-W., Hayar, A., Linster, C., Ennis, M., 2009. Noradrenergic regulation of GABAergic inhibition of main olfactory bulb mitral cells varies as a function of concentration and receptor subtype. J. Neurophysiol. 101, 2472-2484.

ey, N.L., Jardanhazi-Kurutz, D., Terwel, D., Kummer, M.P., Jourdan, F., Didier, A., et al., 2012. Locus coeruleus degeneration exacerbates olfactory deficits in APP/PS1 transgenic mice. Neurobiol. Aging 33 (426), e1-11.

alop, J.J., Chin, J., Roberson, E.D., Wang, J., Thwin, M.T., Bien-Ly, N., et al., 2007. Aberrant excitatory neuronal activity and compensatory remodeling of inhibitory hippocampal circuits in mouse models of Alzheimer's disease. Neuron. 55, 697-711. Palop, J.J., Mucke, L., 2009. Epilepsy and cognitive impairments in Alzheimer disease. Arch. Neurol. 66, 435-440.

Simone, R., Puig, X.S., Gélisse, P., Crespel, A., Genton, P., 2010. Senile myoclonic epilepsy: delineation of a common condition associated with Alzheimer's disease in Down syndrome. Seizure. 19, 383-389.

Bathini, P., Mottas, A., Jaquet, M., Brai, E., Alberi, L., 2018. Progressive signaling changes in the olfactory nerve of patients with Alzheimer's disease. Neurobiol. Aging 76, 80-95.

Lachén-Montes, M., González-Morales, A., Zelaya, M.V., Pérez-Valderrama, E., Ausín, K., Ferrer, I., et al., 2017. Olfactory bulb neuroproteomics reveals a chronological perturbation of survival routes and a disruption of prohibitin complex during Alzheimer's disease progression. Sci. Rep. 7, 9115.

Rey, N.L., Wesson, D.W., Brundin, P., 2018. The olfactory bulb as the entry site for prionlike propagation in neurodegenerative diseases. Neurobiol. Dis. 109, 226-248.

Bergmann, O., Liebl, J., Bernard, S., Alkass, K., Yeung, M.S.Y., Steier, P., et al., 2012. The age of olfactory bulb neurons in humans. Neuron. 74, 634-639.

Bergmann, O., Spalding, K.L., Frisén, J., 2015. Adult neurogenesis in humans. Cold Spring Harb. Perspect. Biol. 7, a018994.

Saiz-Sanchez, D., Ubeda-Bañon, I., de la Rosa-Prieto, C., Argandoña-Palacios, L., GarciaMuñozguren, S., Insausti, R., et al., 2010. Somatostatin, tau, and $\beta$-amyloid within the anterior olfactory nucleus in Alzheimer disease. Exp. Neurol. 223, 347-350.

Attems, J., Alpar, A., Spence, L., McParland, S., Heikenwalder, M., Uhlén, M., et al., 2012. Clusters of secretagogin-expressing neurons in the aged human olfactory tract lack terminal differentiation. Proc. Natl. Acad. Sci. U. S. A. 109, 6259-6264.

Davies, D.C., Brooks, J.W., Lewis, D.A., 1993. Axonal loss from the olfactory tracts in Alzheimer's disease. Neurobiol. Aging 14, 353-357.

Hyman, B.T., Van Hoesen, G.W., Damasio, A.R., Barnes, C.L., 1984. Alzheimer's disease: cell-specific pathology isolates the hippocampal formation. Science. 225, 1168-1170.

Ter Laak, H.J., Renkawek, K., van Workum, F.P., 1994. The olfactory bulb in Alzheimer disease: a morphologic study of neuron loss, tangles, and senile plaques in relation to olfaction. Alzheimer Dis. Assoc. Disord. 8, 38-48.

Brunjes, P.C., Kenerson, M.C. 2010. The anterior olfactory nucleus: quantitative study of dendritic morphology. J. Comp. Neurol. 518, 1603-1616.

Gottfried, J.A., 2010. Central mechanisms of odour object perception. Nat. Rev. Neurosci. $11,628-641$.

Rennaker, R.L., C-FF, C., Ruyle, A.M., Sloan, A.M., Wilson, D.A., 2007. Spatial and temporal distribution of odorant-evoked activity in the piriform cortex. J. Neurosci. 27 1534-1542.

Poo, C., Isaacson, J.S., 2009. Odor representations in olfactory cortex: "Sparse" coding, global inhibition, and oscillations. Neuron. 62, 850-861.

Gottfried, J.A., Winston, J.S., Dolan, R.J., 2006. Dissociable codes of odor quality and odorant structure in human piriform cortex. Neuron. 49, 467-479.

Li, W., Howard, J.D., Gottfried, J.A., 2010a. Disruption of odour quality coding in piriform cortex mediates olfactory deficits in Alzheimer's disease. Brain. 133, 2714-2726.

Arendt, T., 2009. Synaptic degeneration in Alzheimer's disease. Acta Neuropathol. 118, 167-179.

Giannakopoulos, P., Kövari, E., Gold, G., von Gunten, A., Hof, P.R., Bouras, C., 2009. Pathological substrates of cognitive decline in Alzheimer's disease. Front. Neurol. Neurosci. 24, 20-29.

Saiz-Sanchez, D., De la Rosa-Prieto, C., Ubeda-Banon, I., Martinez-Marcos, A., 2015. Interneurons, tau and amyloid- $\beta$ in the piriform cortex in Alzheimer's disease. Brain Struct. Funct. 220, 2011-2025.

Xu, W., Lopez-Guzman, M., Schoen, C., Fitzgerald, S., Lauer, S.L., Nixon, R.A., et al., 2014. Spared piriform cortical single-unit odor processing and odor discrimination in the Tg2576 mouse model of Alzheimer's disease. PLoS One 9, e106431.

Wilson, D.A., 2001. Scopolamine enhances generalization between odor representations in rat olfactory cortex. Learn. Mem. 8, 279-285.

Geula, C., Mesulam, M.M., 1996. Systematic regional variations in the loss of cortical cholinergic fibers in Alzheimer's disease. Cereb. Cortex 6, 165-177.

Van Hoesen, G.W., Parvizi, J., Chu, C.C., 2000. Orbitofrontal cortex pathology in Alzheimer's disease. Cereb. Cortex 10, 243-251.

Bakkour, A., Morris, J.C., Wolk, D.A., Dickerson, B.C., 2013. The effects of aging and Alzheimer's disease on cerebral cortical anatomy: specificity and differential relationships with cognition. Neuroimage. 76, 332-344.

Doty, R.L., Kamath, V., 2014. The influences of age on olfaction: a review. Front. Psychol. $5,20$.

Zald, D.H., Pardo, J.V., 1997. Emotion, olfaction, and the human amygdala: amygdala activation during aversive olfactory stimulation. Proc. Natl. Acad. Sci. U. S. A. 94, 4119-4124.

Halgren, E., 1982. Mental phenomena induced by stimulation in the limbic system. Hum. Neurobiol. 1, 251-260.

Arriagada, P.V., Growdon, J.H., Hedley-Whyte, E.T., Hyman, B.T., 1992. Neurofibrillary tangles but not senile plaques parallel duration and severity of Alzheimer's disease. Neurology. 42, 631-639.

Scott, S.A., DeKosky, S.T., Sparks, D.L., Knox, C.A., Scheff, S.W., 1992. Amygdala cell loss and atrophy in Alzheimer's disease. Ann. Neurol. 32, 555-563.

Vereecken, T.H., Vogels, O.J., Nieuwenhuys, R., 1994. Neuron loss and shrinkage in the amygdala in Alzheimer's disease. Neurobiol. Aging 15, 45-54.

Poulin, S.P., Dautoff, R., Morris, J.C., Barrett, L.F., Dickerson, B.C., 2011. Alzheimer's Disease neuroimaging Initiative. Amygdala atrophy is prominent in early Alzheimer's disease and relates to symptom severity. Psychiatry Res. 194, 7-13.

Biella, G., de Curtis, M., 2000. Olfactory inputs activate the medial entorhinal cortex via the hippocampus. J. Neurophysiol. 83, 1924-1931.

Cleland, T.A., Linster, C., 2003. Central olfactory structures. Neurol. Dis. Therapy. Marcel Dekker AG 57, 165-180.

Stäubli, U., Ivy, G., Lynch, G., 1984. Hippocampal denervation causes rapid forgetting of olfactory information in rats. Proc. Natl. Acad. Sci. U. S. A. 81, 5885-5887.

Wirth, S., Ferry, B., Di Scala, G., 1998. Facilitation of olfactory recognition by lateral entorhinal cortex lesion in rats. Behav. Brain Res. 91, 49-59.

Chapuis, J., Cohen, Y., He, X., Zhang, Z., Jin, S., Xu, F., et al., 2013. Lateral entorhinal modulation of piriform cortical activity and fine odor discrimination. J. Neurosci. 33, 13449-13459.

Stranahan, A.M., Mattson, M.P., 2010. Selective vulnerability of neurons in layer II of the entorhinal cortex during aging and Alzheimer's disease. Neural Plast., 1081902010.

Kretzschmar, H., Braak, H., Alafuzoff, I., Arzberger, T., Del Tredici, K., 2006. Staging of Alzheimer disease-associated neurofibrillary pathology using paraffin sections and immunocytochemistry. Acta Neuropathol. 112, 389-404.

Braak, H., Del Tredici, K., 2015. The preclinical phase of the pathological process underlying sporadic Alzheimer's disease. Brain. 138, 2814-2833.

Braak, H., Braak, E., 1991a. Neuropathological stageing of Alzheimer-related changes. Acta Neuropathol. 82, 239-259.

Wilson, D.A., Xu, W., Sadrian, B., Courtiol, E., Cohen, Y., Barnes, D.C., 2014. Cortical odor processing in health and disease. Prog. Brain Res. 208, 275-305.

Murphy, C., 1999. Loss of olfactory function in dementing disease. Physiol. Behav. 66, 177-182.

Bahar-Fuchs, A., Moss, S., Rowe, C., Savage, G., 2011. Awareness of olfactory deficits in healthy aging, amnestic mild cognitive impairment and Alzheimer's disease. Int. Psychogeriatr. 23, 1097-1106.

Rahayel, S., Frasnelli, J., Joubert, S., 2012. The effect of Alzheimer's disease and Parkinson's disease on olfaction: a meta-analysis. Behav. Brain Res. 231, 60-74.

Mouly, A.-M., Sullivan, R., 2011. Memory and plasticity in the olfactory system: from infancy to adulthood. In: Menini, A. (Ed.), The Neurobiology of Olfaction. Boca Raton (FL): CRC Press/Taylor \& Francis.

Schab, F.R., 1991. Odor memory: taking stock. Psychol. Bull. 109, 242-251.

Eskenazi, B., Cain, W.S., Novelly, R.A., Mattson, R., 1986. Odor perception in temporal 
lobe epilepsy patients with and without temporal lobectomy. Neuropsychologia 24 , $553-562$.

Devanand, D.P., Lee, S., Manly, J., Andrews, H., Schupf, N., Doty, R.L., et al., 2015. Olfactory deficits predict cognitive decline and Alzheimer dementia in an urban community. Neurology 84, 182-189.

Courtiol, E., Wilson, D.A., 2014. Thalamic olfaction: characterizing odor processing in the mediodorsal thalamus of the rat. J. Neurophysiol. 111, 1274-1285.

Sapolsky, R.M., Eichenbaum, H., 1980. Thalamocortical mechanisms in odor-guided behavior. II. Effects of lesions of the mediodorsal thalamic nucleus and frontal cortex on odor preferences and sexual behavior in the hamster. Brain Behav. Evol. 17, 276-290.

Sela, L., Sacher, Y., Serfaty, C., Yeshurun, Y., Soroker, N., Sobel, N., 2009. Spared and impaired olfactory abilities after thalamic lesions. J. Neurosci. 29, 12059-12069.

Slotnick, B.M., Risser, J.M., 1990. Odor memory and odor learning in rats with lesions of the lateral olfactory tract and mediodorsal thalamic nucleus. Brain Res. 529, 23-29.

Asahi, T., Kawagoe, T., Tamura, R., Uwano, T., Nishijo, H., Eifuku, S., et al., 2007. Neural correlates of stimulus-reward association in the rat mediodorsal thalamus. Neuroreport. 18, 683.

Tham, W.W.P., Stevenson, R.J., Miller, L.A., 2011a. The impact of mediodorsal thalamic lesions on olfactory attention and flavor perception. Brain Cogn. 77, 71-79.

Tham, W.W.P., Stevenson, R.J., Miller, L.A., 2009. The functional role of the medio dorsal thalamic nucleus in olfaction. Brain Res. Rev. 62, 109-126.

Zelano, C., Mohanty, A., Gottfried, J.A., 2011. Olfactory predictive codes and stimulus templates in piriform cortex. Neuron. 72, 178-187.

Tham, W.W.P., Stevenson, R.J., Miller, L.A., 2011b. The role of the mediodorsal thalamic nucleus in human olfaction. Neurocase. 17, 148-159.

Veldhuizen, M.G., Small, D.M., 2011. Modality-specific neural effects of selective attention to taste and odor. Chem. Senses 36, 747-760.

Plailly, J., Howard, J.D., Gitelman, D.R., Gottfried, J.A., 2008. Attention to odor modulates thalamocortical connectivity in the human brain. J. Neurosci. 28, 5257-5267.

Paskavitz, J.F., Lippa, C.F., Hamos, J.E., 1995. Role of the dorsomedial nucleus of the thalamus in Alzheimer's disease. J. Geriatric psycnet.apa.org;Available: https:// psycnet.apa.org/record/1995-30016-001.

Braak, H., Braak, E., 1991b. Alzheimer's disease affects limbic nuclei of the thalamus. Acta Neuropathol. 81, 261-268.

Zarei, M., Patenaude, B., Damoiseaux, J., Morgese, C., Smith, S., Matthews, P.M., et al., 2010. Combining shape and connectivity analysis: an MRI study of thalamic degeneration in Alzheimer's disease. Neuroimage. 49, 1-8.

Vasavada, M.M., Martinez, B., Wang, J., Eslinger, P.J., Gill, D.J., Sun, X., et al., 2017. Central olfactory dysfunction in alzheimer's disease and mild cognitive impairment: a functional MRI study. [Internet]. J. Alzheimer Dis. 359-368. https://doi.org/10. 3233/jad-170310.

Chételat, G., Landeau, B., Eustache, F., Mézenge, F., Viader, F., de la Sayette, V., et al., 2005. Using voxel-based morphometry to map the structural changes associated with rapid conversion in MCI: a longitudinal MRI study. Neuroimage. 27, 934-946.

org, C., Riedl, V., Mühlau, M., Calhoun, V.D., Eichele, T., Läer, L., et al., 2007. Selective changes of resting-state networks in individuals at risk for Alzheimer's disease. Proc. Natl. Acad. Sci. U. S. A. 104, 18760-18765

Yi, H.-A., Möller, C., Dieleman, N., Bouwman, F.H., Barkhof, F., Scheltens, P., et al., 2016. Relation between subcortical grey matter atrophy and conversion from mild cognitive impairment to Alzheimer's disease. J. Neurol. Neurosurg. Psychiatry 87, 425-432.

Pedro, T., Weiler, M., Yasuda, C.L., D’Abreu, A., Damasceno, B.P., Cendes, F., et al., 2012. Volumetric brain changes in thalamus, corpus callosum and medial temporal structures: mild Alzheimer's disease compared with amnestic mild cognitive impairment. Dement. Geriatr. Cogn. Disord. 34, 149-155.

Reinvang, I., Grambaite, R., Espeseth, T., 2012. Executive dysfunction in MCI: subtype or early symptom. Int. J. Alzheimer's Dis. Hindawi. https://doi.org/10.1155/2012/ 936272. 2012.

Gottfried, J.A., 2006. Smell: central nervous processing. Adv. Otorhinolaryngol. 63, 44-69.

Gottfried, J.A., Zald, D.H., 2005. On the scent of human olfactory orbitofrontal cortex: meta-analysis and comparison to non-human primates. Brain Res. Rev. 50, 287-304.

Gottfried, J.A., Deichmann, R., Winston, J.S., Dolan, R.J., 2002. Functional heterogeneity in human olfactory cortex: an event-related functional magnetic resonance imaging study. J. Neurosci. 22, 10819-10828.

Anderson, A.K., Christoff, K., Stappen, I., Panitz, D., Ghahremani, D.G., Glover, G., et al., 2003. Dissociated neural representations of intensity and valence in human olfaction. Nat. Neurosci. 6, 196-202.

Rolls, E.T., Kringelbach, M.L., de Araujo, I.E.T., 2003. Different representations of pleasant and unpleasant odours in the human brain. Eur. J. Neurosci. 18, 695-703.

Small, D.M., Zatorre, R.J., Dagher, A., Evans, A.C., Jones-Gotman, M., 2001. Changes in brain activity related to eating chocolate: from pleasure to aversion. Brain. 124, 1720-1733.

O’Doherty, J., Winston, J., Critchley, H., Perrett, D., Burt, D.M., Dolan, R.J., 2003. Beauty in a smile: the role of medial orbitofrontal cortex in facial attractiveness. Neuropsychologia. 41, 147-155.

Schoenbaum, G., Eichenbaum, H., 1995. Information coding in the rodent prefrontal cortex. II. Ensemble activity in orbitofrontal cortex. J. Neurophysiol. 74, 751-762.

Jones-Gotman, M., Zatorre, R.J., 1988. Olfactory identification deficits in patients with focal cerebral excision. Neuropsychologia. 26, 387-400.

Potter, H., Butters, N., 1980. An assessment of olfactory deficits in patients with damage to prefrontal cortex. Neuropsychologia. 18, 621-628.

Li, W., Lopez, L., Osher, J., Howard, J.D., Parrish, T.B., Gottfried, J.A., 2010b. Right orbitofrontal cortex mediates conscious olfactory perception. Psychol. Sci. 21, 1454-1463.

Tekin, S., Mega, M.S., Masterman, D.M., Chow, T., Garakian, J., Vinters, H.V., et al., 2001.
Orbitofrontal and anterior cingulate cortex neurofibrillary tangle burden is associated with agitation in Alzheimer disease. Ann. Neurol. 49, 355-361.

Gordon, B.A., McCullough, A., Mishra, S., Blazey, T.M., Su, Y., Christensen, J., et al., 2018. Cross-sectional and longitudinal atrophy is preferentially associated with tau rather than amyloid $\beta$ positron emission tomography pathology. Alzheimers Dement 10, 245-252.

Wesson, D.W., Levy, E., Nixon, R.A., Wilson, D.A., 2010. Olfactory dysfunction correlates with Amyloid- $\beta$ burden in an alzheimer's disease mouse model. J. Neurosci. Soc. Neurosci. 30, 505-514.

Frisoni, G.B., Prestia, A., Rasser, P.E., Bonetti, M., Thompson, P.M., 2009. In vivo mapping of incremental cortical atrophy from incipient to overt Alzheimer's disease. J. Neurol. 256, 916-924.

Itzhaki, R.F., Lin, W.R., Shang, D., Wilcock, G.K., Faragher, B., Jamieson, G.A., 1997. Herpes simplex virus type 1 in brain and risk of Alzheimer's disease. Lancet 349, 241-244.

Jamieson, G.A., Maitland, N.J., Wilcock, G.K., Craske, J., Itzhaki, R.F., 1991. Latent herpes simplex virus type 1 in normal and Alzheimer's disease brains. J. Med. Virol. $33,224-227$.

Miklossy, J., 2008a. Chronic inflammation and amyloidogenesis in alzheimer's diseaseRole of spirochetes 1. J. Alzheimers Dis. 13, 381-391 IOS Press.

Miklossy, J., Kasas, S., Janzer, R.C., Ardizzoni, F., Van der Loos, H., 1994. Further ultrastructural evidence that spirochaetes may play a role in the aetiology of Alzheimer's disease. Neuroreport. 5, 1201-1204.

Balin, B.J., Gérard, H.C., Arking, E.J., Appelt, D.M., Branigan, P.J., Abrams, J.T., et al., 1998. Identification and localization of Chlamydia pneumoniae in the Alzheimer's brain. Med. Microbiol. Immunol. 187, 23-42.

Miklossy, J., 2016. Bacterial amyloid and DNA are important constituents of senile plaques: further evidence of the spirochetal and biofilm nature of senile plaques. J. Alzheimers Dis. 53, 1459-1473.

Wozniak, M.A., Itzhaki, R.F., Shipley, S.J., Dobson, C.B., 2007. Herpes simplex virus infection causes cellular beta-amyloid accumulation and secretase upregulation. Neurosci. Lett. 429, 95-100.

Moir, R.D., Lathe, R., Tanzi, R.E., 2018. The antimicrobial protection hypothesis of Alzheimer's disease. Alzheimers Dement. 14, 1602-1614.

Wozniak, M.A., Mee, A.P., Itzhaki, R.F., 2009. Herpes simplex virus type 1 DNA is located within Alzheimer's disease amyloid plaques. J. Pathol. 217, 131-138.

Yount, N.Y., Bayer, A.S., Xiong, Y.Q., Yeaman, M.R., 2006. Advances in antimicrobial peptide immunobiology. Biopolymers. 84, 435-458.

Little, C.S., Hammond, C.J., MacIntyre, A., Balin, B.J., Appelt, D.M., 2004. Chlamydia pneumoniae induces Alzheimer-like amyloid plaques in brains of BALB/c mice. Neurobiol. Aging 25, 419-429.

Little, C.S., Joyce, T.A., Hammond, C.J., Matta, H., Cahn, D., Appelt, D.M., et al., 2014 Detection of bacterial antigens and Alzheimerâ $\epsilon^{\mathrm{TM}_{\mathrm{S}}}$ disease-like pathology in the central nervous system of BALB/c mice following intranasal infection with a laboratory isolate of Chlamydia pneumoniae [Internet]. Front. Aging Neurosci. https:// doi.org/10.3389/fnagi.2014.00304.

Wozniak, M.A., Frost, A.L., Preston, C.M., Itzhaki, R.F., 2011. Antivirals reduce the formation of key Alzheimer's disease molecules in cell cultures acutely infected with herpes simplex virus type 1. PLoS One 6, e25152.

Cheng, S.-B., Ferland, P., Webster, P., Bearer, E.L., 2011. Herpes simplex virus dances with amyloid precursor protein while exiting the cell [Internet]. PLoS One e17966. https://doi.org/10.1371/journal.pone.0017966.

Shipley, S.J., Parkin, E.T., Itzhaki, R.F., Dobson, C.B., 2005. Herpes simplex virus interferes with amyloid precursor protein processing. BMC Microbiol. 5, 48.

Kumar, D.V., Kumar, D.K.V., Choi, S.H., Washicosky, K.J., Eimer, W.A., Tucker, S., et al., 2016. Amyloid- $\beta$ peptide protects against microbial infection in mouse and worm models of Alzheimer's disease [Internet]. Sci. Transl. Med. https://doi.org/10.1126/ scitranslmed.aaf1059. pp. 340ra72-340ra72.

Ezzat, K., Pernemalm, M., Pålsson, S., Roberts, T.C., Järver, P., Dondalska, A., et al., 2019. The viral protein corona directs viral pathogenesis and amyloid aggregation. Nat. Commun. 10, 2331.

Lokensgard, J.R., Hu, S., Sheng, W., vanOijen, M., Cox, D., Cheeran, M.C.-J., et al., 2001. Robust expression of TNF- $\alpha$, IL-1 $\beta$, RANTES, and IP-10 by human microglial cells during nonproductive infection with herpes simplex virus. J. Neurovirol. 7, 208-219.

Itzhaki, R.F., Wozniak, M.A., 2008. Herpes simplex virus type 1 in Alzheimer's disease: the enemy within. J. Alzheimers Dis. 13, 393-405.

Burgos, J.S., Ramirez, C., Sastre, I., Valdivieso, F., 2006. Effect of apolipoprotein E on the cerebral load of latent herpes simplex virus type 1 DNA. J. Virol. 80, 5383-5387.

Valdivieso, F., Guzman-Sanchez, F., Burgos, J.S., 2012. Aging-related neurostructural, neuropathological, and behavioral changes associated with herpes simplex virus type 1 brain infection in mice. J. Alzheimers Dis. 30, 779-790.

Liu, C.-C., Zhao, N., Fu, Y., Wang, N., Linares, C., Tsai, C.-W., et al., 2017. ApoE4 accelerates early seeding of amyloid pathology. Neuron. 96, 1024-1032 e3.

Martin, C., Aguila, B., Araya, P., Vio, K., Valdivia, S., Zambrano, A., et al., 2014. Inflammatory and neurodegeneration markers during asymptomatic HSV-1 reactivation. J. Alzheimers Dis. 39, 849-859.

Readhead, B., Haure-Mirande, J.-V., Funk, C.C., Richards, M.A., Shannon, P., Haroutunian, V., et al., 2018. Multiscale analysis of independent alzheimer's cohorts finds disruption of molecular, genetic, and clinical networks by human herpesvirus. Neuron. 99, 64-82 e7.

Donati, D., Martinelli, E., Cassiani-Ingoni, R., Ahlqvist, J., Hou, J., Major, E.O., et al., 2005. Variant-specific tropism of human herpesvirus 6 in human astrocytes. J. Virol. 79, 9439-9448.

Leibovitch, E.C., Caruso, B., Ha, S.K., Schindler, M.K., Lee, N.J., Luciano, N.J., et al., 2018. Herpesvirus trigger accelerates neuroinflammation in a nonhuman primate model of multiple sclerosis. Proc. Natl. Acad. Sci. U. S. A. 115, 11292-11297. 
Harberts, E., Yao, K., Wohler, J.E., Maric, D., Ohayon, J., Henkin, R., et al., 2011. Human herpesvirus-6 entry into the central nervous system through the olfactory pathway. Proc. Natl. Acad. Sci. U. S. A. 108, 13734-13739.

Gérard, H.C., Wildt, K.L., Whittum-Hudson, J.A., Lai, Z., Ager, J., Hudson, A.P., 2005. The load of Chlamydia pneumoniae in the Alzheimer's brain varies with APOE genotype. Microb. Pathog. 39, 19-26.

Boelen, E., Steinbusch, H.W.M., van der Ven AJAM, G.G., Bruggeman, C.A., Stassen, F.R.M., 2007. Chlamydia pneumoniae infection of brain cells: an in vitro study. Neurobiol. Aging 28, 524-532.

Miklossy, J., 2008b. Biology and neuropathology of dementia in syphilis and Lyme disease. Handb. Clin. Neurol. 89, 825-844.

Mann, D.M., Tucker, C.M., Yates, P.O., 1988. Alzheimer's disease: an olfactory connection? Mech. Ageing Dev. 42, 1-15.

Miklossy, J., 2011. Alzheimer's disease - a neurospirochetosis. Analysis of the evidence following Koch's and Hill's criteria. J. Neuroinfl. 8, 90.

MacDonald, A.B., Miranda, J.M., 1987. Concurrent neocortical borreliosis and Alzheimer's disease. Hum. Pathol. 18, 759-761.

Vetere, A., D’Aniello, A., Fisher, G.H., Cusano, G., Chavez, M., Petrucelli, L., 1992. Presence of D-alanine in proteins of normal and Alzheimer human brain. Brain Res. $592,44-48$

Miklossy, J., Darekar, P., Gern, L., Janzer, R.C., Bosman, F.T., 1996. Bacterial peptidoglycan in neuritic plaques in Alzheimer's disease. Azheimer's Res. 2, 95-100.

Miklossy, J., Martins, R.N., 2008. Chronic Inflammation and Amyloidogenesis in Alzheimer's Disease: The Emerging Role of Infection [Internet]. J. Alzheimer Dis. https://doi.org/10.3233/jad-2008-13401. pp. 357-357.

Miklossy, J., Khalili, K., Gern, L., Ericson, R.L., Darekar, P., Bolle, L., et al., 2004. Borrelia burgdorferi persists in the brain in chronic lyme neuroborreliosis and may be associated with Alzheimer disease. J. Alzheimers Dis. 6, 639-649 discussion 673-81.

Nicolson, G.L., 2008. Chronic bacterial and viral infections in neurodegenerative and neurobehavioral diseases. Lab Med. Narnia 39, 291-299.

Gylfe, A., Wahlgren, M., Fahlén, L., Bergström, S., 2002. Activation of latent Lyme borreliosis concurrent with a herpes simplex virus type 1 infection. Scand. J. Infect. Dis. 34, 922-924.

Sellati, T.J., Bouis, D.A., Kitchens, R.L., 1998. Treponema pallidum and Borrelia burgdorferi lipoproteins and synthetic lipopeptides activate monocytic cells via a CD14dependent pathway distinct from that used .... J. Am. Assoc. Immnol Available: http://www.jimmunol.org/content/160/11/5455.short.

Koskinen, K., Reichert, J.L., Hoier, S., Schachenreiter, J., Duller, S., Moissl-Eichinger, C. et al., 2018. The nasal microbiome mirrors and potentially shapes olfactory function. Sci Rep. Nat. Publ. Group 8, 1296.

- Dominguez-Bello, M.G., Costello, E.K., Contreras, M., Magris, M., Hidalgo, G., Fierer, N., et al., 2010. Delivery mode shapes the acquisition and structure of the initial microbiota across multiple body habitats in newborns. Proc. Natl. Acad. Sci. U. S. A. 107, 11971-11975.

Frenkel, D., Solomon, B., 2002. Filamentous phage as vector-mediated antibody delivery to the brain. Proc. Natl. Acad. Sci. U. S. A. 99, 5675-5679.

trandberg, T.E., Pitkala, K.H., Linnavuori, K.H., Tilvis, R.S., 2003. Impact of viral and bacterial burden on cognitive impairment in elderly persons with cardiovascular diseases. Stroke. 34, 2126-2131.

AATM, B., Biesbroek, G., Trzcinski, K., Sanders, E.A.M., Bogaert, D., 2013. Viral and bacterial interactions in the upper respiratory tract. PLoS Pathog. 9, e1003057. Wozniak, M.A., Itzhaki, R.F., 2013. Intravenous immunoglobulin reduces beta amyloid and abnormal tau formation caused by herpes simplex virus type 1 . J.

Neuroimmunol. 257, 7-12.

zeng, N.-S., Chung, C.-H., Lin, F.-H., Chiang, C.-P., Yeh, C.-B., Huang, S.-Y., et al., 2018. Anti-herpetic medications and reduced risk of dementia in patients with herpes simplex virus Infections-a nationwide, population-based cohort study in Taiwan Neurotherapeutics. 15, 417-429.

Dominy, S.S., Lynch, C., Ermini, F., Benedyk, M., Marczyk, A., Konradi, A., et al., 2019. Porphyromonas gingivalis in Alzheimer's disease brains: evidence for disease causation and treatment with small-molecule inhibitors. Sci. Adv. 5, eaau3333.

Pisa, D., Alonso, R., Juarranz, A., Rábano, A., Carrasco, L., 2015a. Direct visualization of fungal infection in brains from patients with Alzheimer's disease. J. Alzheimers Dis. 43, 613-624.

Pisa, D., Alonso, R., Rábano, A., Rodal, I., Carrasco, L., 2015b. Different brain regions are infected with Fungi in alzheimer's disease. Sci. Rep. 5, 15015.

Pisa, D., Alonso, R., Marina, A.I., Rábano, A., Carrasco, L., 2018. Human and microbial proteins from Corpora Amylacea of alzheimer's disease. Sci. Rep. 8, 9880.

Vogt, N.M., Kerby, R.L., Dill-McFarland, K.A., Harding, S.J., Merluzzi, A.P., Johnson, S.C., et al., 2017. Gut microbiome alterations in Alzheimer's disease. Sci. Rep. 7, 13537.

Heneka, M.T., Golenbock, D.T., Latz, E., 2015. Innate immunity in Alzheimer's disease. Nat. Immunol. 16, 229-236.

Soscia, S.J., Kirby, J.E., Washicosky, K.J., Tucker, S.M., Ingelsson, M., Hyman, B., et al., 2010. The Alzheimer's disease-associated amyloid beta-protein is an antimicrobial peptide. PLoS One 5, e9505.

LAMP: A database links to antimicrobial peptides [Internet].[cited 29 Jul 2019]. Available: http://biotechlab.fudan.edu.cn/database/lamp/index.php.

Tomlinson, J.J., Shutinoski, B., Dong, L., Meng, F., Elleithy, D., Lengacher, N.A., et al., 2017. Holocranohistochemistry enables the visualization of $\alpha$-synuclein expression in the murine olfactory system and discovery of its systemic anti-microbial effects. J. Neural Transm. 124, 721-738.

Akimoto, H., 2003. Global air quality and pollution. Science. 302, 1716-1719.

Simkhovich, B.Z., Kleinman, M.T., Kloner, R.A., 2008. Air pollution and cardiovascular injury epidemiology, toxicology, and mechanisms. J. Am. Coll. Cardiol. 52, 719-726.

Calderón-Garcidueñas, L., Franco-Lira, M., Henríquez-Roldán, C., Osnaya, N., GonzálezMaciel, A., Reynoso-Robles, R., et al., 2010. Urban air pollution: influences on olfactory function and pathology in exposed children and young adults. Exp. Toxicol. Pathol. 62, 91-102.

Calderon-Garciduenas, L., Azzarelli, B., Acuna, H., Garcia, R., Gambling, T.M., Osnaya, N., et al., 2002. Air pollution and brain damage. Toxicol. Pathol. 30, 373-389 Sage Publications Sage CA: Los Angeles, CA.

Calderon-Garciduenas, L., Maronpot, R.R., Torres-Jardon, R., Henriquez-Roldan, C., Schoonhoven, R., Acuna-Ayala, H., et al., 2003. DNA damage in nasal and brain tissues of canines exposed to air pollutants is associated with evidence of chronic brain inflammation and neurodegeneration. Toxicol Pathol. SAGE Publ. Inc. 31, 524-538.

Chen, P., Miah, M.R., Aschner, M., 2016. Metals and Neurodegen. F1000Res. 5. https:// doi.org/10.12688/f1000research.7431.1.

Calderón-Garcidueñas, L., Solt, A.C., Henríquez-Roldán, C., Torres-Jardón, R., Nuse, B., Herritt, L., et al., 2008a. Long-term air pollution exposure is associated with neuroinflammation, an altered innate immune response, disruption of the blood-brain barrier, ultrafine particulate deposition, and accumulation of amyloid $\beta-42$ and $\alpha$ Synuclein in children and young adults [Internet]. Toxicol. Pathol. 289-310. https:// doi.org/10.1177/0192623307313011.

Calderón-Garcidueñas, L., Mora-Tiscareño, A., Ontiveros, E., Gómez-Garza, G., BarragánMejía, G., Broadway, J., et al., 2008b. Air pollution, cognitive deficits and brain abnormalities: a pilot study with children and dogs. Brain Cogn. 68, 117-127.

Hoffman, H.J., Rawal, S., Li, C.-M., Duffy, V.B., 2016. New chemosensory component in the U.S. National Health and Nutrition Examination Survey (NHANES): first-year results for measured olfactory dysfunction. Rev. Endocr. Metab. Disord. 17, 221-240.

Richardson, J.R., Roy, A., Shalat, S.L., von Stein, R.T., Hossain, M.M., Buckley, B., et al., 2014. Elevated serum pesticide levels and risk for Alzheimer disease. JAMA Neurol. 71, 284-290.

Parrón, T., Requena, M., Hernández, A.F., Alarcón, R., 2011. Association between environmental exposure to pesticides and neurodegenerative diseases. Toxicol. Appl. Pharmacol. 256, 379-385.

Steenland, K., Dick, R.B., Howell, R.J., Chrislip, D.W., Hines, C.J., Reid, T.M., et al., 2000. Neurologic function among termiticide applicators exposed to chlorpyrifos. Environ. Health Perspect. 108, 293-300.

Gottlieb, S., 2000. Head injury doubles the risk of Alzheimer's disease. BMJ. British Med. J. Publ. Group 321, 1100

Han, P., Winkler, N., Hummel, C., Hähner, A., Gerber, J., Hummel, T., 2018. Alterations of brain gray matter density and olfactory bulb volume in patients with olfactory loss after traumatic brain injury. J. Neurotrauma 35, 2632-2640.

Proskynitopoulos, P.J., Stippler, M., Kasper, E.M., 2016. Post-traumatic anosmia in patients with mild traumatic brain injury (mTBI): a systematic and illustrated review. Surg. Neurol. Int. 7, S263-75.

Holbrook, E.H., Leopold, D.A., Schwob, J.E., 2005. Abnormalities of axon growth in human olfactory mucosa. Laryngoscope. 115, 2144-2154.

Ponsford, J., McLaren, A., Schönberger, M., Burke, R., Rudzki, D., Olver, J., et al., 2011 The association between apolipoprotein $\mathrm{E}$ and traumatic brain injury severity and functional outcome in a rehabilitation sample. J. Neurotrauma 28, 1683-1692.

Nathoo, N., Chetty, R., van Dellen, J.R., Barnett, G.H., 2003. Genetic vulnerability following traumatic brain injury: the role of apolipoprotein E. Mol Pathol. 56, 132-136.

Lane, A.P., Turner, J., May, L., Reed, R., 2010. A genetic model of chronic rhinosinusitisassociated olfactory inflammation reveals reversible functional impairment and dramatic neuroepithelial reorganization. J. Neurosci. 30, 2324-2329.

Hüttenbrink, K.-B., Hummel, T., Berg, D., Gasser, T., Hähner, A., 2013. Olfactory dysfunction: common in later life and early warning of neurodegenerative disease. Arztebl. Int. 110, 1-7 e1.

Okada, K., Kanaya, K., Kondo, K., Suzukawa, K., Sakamoto, T., Kikuta, S., et al., 2014. Innate immune responses and neuroepithelial degeneration and regeneration in the mouse olfactory mucosa induced by intranasal administration of Poly(I:C). Cell Tissue Res. 357, 279-299.

Borders, A.S., Getchell, M.L., Etscheidt, J.T., van Rooijen, N., Cohen, D.A., Getchell, T.V., 2007. Macrophage depletion in the murine olfactory epithelium leads to increased neuronal death and decreased neurogenesis. J. Comp. Neurol. 501, 206-218.

Chen, M., Reed, R.R., Lane, A.P., 2017. Acute inflammation regulates neuroregeneration through the NF-kB pathway in olfactory epithelium. Proc. Natl. Acad. Sci. U. S. A. 114, 8089-8094.

Child, K.M., Herrick, D.B., Schwob, J.E., Holbrook, E.H., Jang, W., 2018. The neuroregenerative capacity of olfactory stem cells is not limitless: implications for aging. J. Neurosci. https://doi.org/10.1523/JNEUROSCI.3261-17.2018.

Holbrook, E.H., Wu, E., Curry, W.T., Lin, D.T., Schwob, J.E., 2011. Immunohistochemical characterization of human olfactory tissue. Laryngoscope. 121, 1687-1701.

Kanaya, K., Kondo, K., Suzukawa, K., Sakamoto, T., Watanabe, K., Ushio, M., et al., 2010 Age-related changes in cell dynamics of the postnatal mouse olfactory neuroepithelium: cell proliferation, neuronal differentiation, and cell death [Internet]. J. Comp. Neurol. 1962-1975. https://doi.org/10.1002/cne.22316.

Doty, R.L., Mishra, A., 2001. Olfaction and its alteration by nasal obstruction, rhinitis, and rhinosinusitis. Laryngoscope. 111, 409-423.

Farbman, A.I., Buchholz, J.A., Suzuki, Y., Coines, A., Speert, D., 1999. A molecular basis of cell death in olfactory epithelium. J. Comp. Neurol. 414, 306-314.

Suzuki, Y., Farbman, A.I., 2000. Tumor necrosis factor-alpha-induced apoptosis in ol factory epithelium in vitro: possible roles of caspase 1 (ICE), caspase 2 (ICH-1), and caspase 3 (CPP32). Exp. Neurol. 165, 35-45.

Hasegawa-Ishii, S., Shimada, A., Imamura, F., 2017. Lipopolysaccharide-initiated persistent rhinitis causes gliosis and synaptic loss in the olfactory bulb. Sci. Rep. 7 , 11605.

Teranishi, M., Yasue, M., Sugiura, S., Uchida, Y., Otake, H., Sakurai, T., et al., 2015. Prevalence of sinusitis detected by magnetic resonance imaging in subjects with dementia or alzheimer's disease. Curr. Alzheimer Res. 12, 1006-1011. 
Chung, S.-D., Hung, S.-H., Lin, H.-C., Kang, J.-H., 2015. Dementia is associated with chronic rhinosinusitis: a population-based case-controlled study. Am. J. Rhinol. Allergy 29, 44-47.

Bower, J.H., Maraganore, D.M., Peterson, B.J., Ahlskog, J.E., Rocca, W.A., 2006. Immunologic diseases, anti-inflammatory drugs, and Parkinson disease: a case-control study. Neurology. 67, 494-496.

Gonzalez, B., Abud, E.M., Abud, A.M., Poon, W.W., Gylys, K.H., 2017. Tau spread, apolipoprotein e, inflammation, and more: rapidly evolving basic science in alzheimer disease. Neurol. Clin. 35, 175-190.

Falgarone, G., Chiocchia, G., 2009. Clusterin: a multifacet protein at the crossroad of inflammation and autoimmunity. Chapter 8. Adv. Cancer Res. 104, 139-170.

Hong, G.H., Kwon, H.-S., Moon, K.-A., Park, S.Y., Park, S., Lee, K.Y., et al., 2016. Clusteri modulates allergic airway inflammation by attenuating CCL20-Mediated dendritic cell recruitment. J. Immunol. 196, 2021-2030.

Fahrenhold, M., Rakic, S., Classey, J., Brayne, C., Ince, P.G., Nicoll, J.A.R., et al., 2018 TREM2 expression in the human brain: a marker of monocyte recruitment? Brain Pathol. 28, 595-602.

Jay, T.R., Miller, C.M., Cheng, P.J., Graham, L.C., Bemiller, S., Broihier, M.L., et al., 2015 TREM2 deficiency eliminates TREM2 + inflammatory macrophages and ameliorates pathology in Alzheimer's disease mouse models. J. Exp. Med. 212, 287-295.

Shi, Y., Holtzman, D.M., 2018. Interplay between innate immunity and Alzheimer disease: APOE and TREM2 in the spotlight. Nat. Rev. Immunol. 18, 759-772.

Finch, C.E., Morgan, T.E., 2007. Systemic inflammation, infection, ApoE alleles, and Alzheimer disease: a position paper. Curr. Alzheimer Res. 4, 185-189.

Burt, T.D., Agan, B.K., Marconi, V.C., He, W., Kulkarni, H., Mold, J.E., et al., 2008. Apolipoprotein (apo) E4 enhances HIV-1 cell entry in vitro, and the APOE 4/ 4 genotype accelerates HIV disease progression [Internet]. Proc. Natl. Acad. Sci. 8718-8723. https://doi.org/10.1073/pnas.0803526105.

Hishiki, T., Shimizu, Y., Tobita, R., Sugiyama, K., Ogawa, K., Funami, K., et al., 2010. Infectivity of hepatitis $\mathrm{C}$ virus is influenced by association with apolipoprotein $\mathrm{E}$ isoforms. J. Virol. 84, 12048-12057.

Yin, Z., Xiong, C., Wang, Y., Zhou, X., Yan, S.-K., 2010. Investigation of the relationship between apolipoprotein $\mathrm{E}$ gene polymorphisms and hepatitis B virus infection in northern China. Clin. Chem. Lab. Med. 48, 1803-1807.

de Bont, N., Netea, M.G., Demacker, P.N., Verschueren, I., Kullberg, B.J., van Dijk, K.W. et al., 1999. Apolipoprotein E knock-out mice are highly susceptible to endotoxemia and Klebsiella pneumoniae infection. J. Lipid Res. 40, 680-685.

Van Oosten, M., Rensen, P.C., Van Amersfoort, E.S., Van Eck, M., Van Dam, A.M., Breve, J.J., et al., 2001. Apolipoprotein E protects against bacterial lipopolysaccharide-induced lethality. A new therapeutic approach to treat gram-negative sepsis. J. Biol. Chem. 276, 8820-8824.

Kattan, O.M., Kasravi, F.B., Elford, E.L., Schell, M.T., Harris, H.W., 2008. Apolipoprotein E-mediated immune regulation in sepsis. J. Immunol. 181, 1399-1408.

Murphy, C., Solomon, E.S., Haase, L., Wang, M., Morgan, C.D., 2009. Olfaction in aging and alzheimer's disease: event-related potentials to a cross-modal odor-recognition memory task discriminate ApoE $\varepsilon 4+$ and ApoE $\varepsilon 4$ - individuals. Ann. N. Y. Acad. Sci. Wiley Online Lib. 1170, 647-657.

Calhoun-Haney, R., Murphy, C., 2005. Apolipoprotein epsilon4 is associated with more rapid decline in odor identification than in odor threshold or Dementia Rating Scale scores. Brain Cogn. 58, 178-182.

Gilbert, P.E., Murphy, C., 2004. The effect of the ApoE $\varepsilon 4$ allele on recognition memory for olfactory and visual stimuli in patients with pathologically confirmed alzheimer's disease, probable alzheimer's disease, and healthy elderly controls [Internet]. J. Clin. Exp. Neuropsychol. 779-794. https://doi.org/10.1080/13803390490509439.

Bacon, A.W., Bondi, M.W., Salmon, D.P., Murphy, C., 1998. Very early changes in ol factory functioning due to alzheimer's disease and the role of apolipoprotein e in Olfactiona. Annals NY Acad Sci. 855, 723-731.

Baitsch, D., Bock, H.H., Engel, T., Telgmann, R., Müller-Tidow, C., Varga, G., et al., 2011. Apolipoprotein E induces antiinflammatory phenotype in macrophages. Arterioscler. Thromb. Vasc. Biol. 31, 1160-1168.

Yin, C., Ackermann, S., Ma, Z., Mohanta, S.K., Zhang, C., Li, Y., et al., 2019. ApoE attenuates unresolvable inflammation by complex formation with activated C1q. Nat. Med. 25, 496-506.

Nathan, B.P., Nannapaneni, S., Gairhe, S., Nwosu, I., Struble, R.G., 2007. The distribution of apolipoprotein E in mouse olfactory epithelium. Brain Res. 1137, 78-83.

Nathan, B.P., Nisar, R., Short, J., Randall, S., Grissom, E., Griffin, G., et al., 2005. Delayed olfactory nerve regeneration in ApoE-deficient mice. Brain Res. 1041, 87-94.

Hussain, A., Luong, M., Pooley, A., Nathan, B.P., 2013. Isoform-specific effects of apoE on neurite outgrowth in olfactory epithelium culture. J. Biomed. Sci. 20, 49.

Wetter, S., Murphy, C., 2001. Apolipoprotein E epsilon4 positive individuals demonstrate delayed olfactory event-related potentials. Neurobiol. Aging 22, 439-447.
Covington, J.W., Geisler, M.W., Polich, J., Murphy, C., 1999. Normal aging and odor intensity effects on the olfactory event-related potential. Int. J. Psychophysiol. 32, 205-214.

Prinz, M., Priller, J., 2017. The role of peripheral immune cells in the CNS in steady state and disease. Nat. Neurosci. 20, 136-144.

Cross, D.J., Anzai, Y., Petrie, E.C., Martin, N., Richards, T.L., Maravilla, K.R., et al., 2013. Loss of olfactory tract integrity affects cortical metabolism in the brain and olfactory regions in aging and mild cognitive impairment. J. Nucl. Med. 54, 1278-1284.

Gillet, L., Frederico, B., Stevenson, P.G., 2015. Host entry by gamma-herpesviruses-lessons from animal viruses? Curr. Opin. Virol. 15, 34-40.

Saiki, K., Fukazawa, O., Asaka, H., Takagi, S., 1994. T\&amp;T olfactometer for standardized olfactory test and its uses [Internet]. Olfaction and Taste XIhttps://doi.org/10. 1007/978-4-431-68355-1_140. pp. 340-340.

Fortier, I., Ferraris, J., Mergler, D., 1991. Measurement precision of an olfactory per ception threshold test for use in field studies. Am. J. Ind. Med. 20, 495-504.

Peters, J.M., Hummel, T., Kratzsch, T., Lötsch, J., Skarke, C., Frölich, L., 2003. Olfactory function in mild cognitive impairment and alzheimer's disease: an investigation using psychophysical and electrophysiological techniques. AJP. Am. Psychiatric Publ. 160, 1995-2002.

Förster, S., Vaitl, A., Teipel, S.J., Yakushev, I., Mustafa, M., la Fougère, C., et al., 2010. Functional representation of olfactory impairment in early Alzheimer's disease. J. Alzheimers Dis. 22, 581-591.

Doty, R.L., Reyes, P.F., Gregor, T., 1987. Presence of both odor identification and detection deficits in Alzheimer's disease. Brain Res. Bull. 18, 597-600.

Knupfer, L., Spiegel, R., 1986. Differences in olfactory test performance between normal aged, Alzheimer and vascular type dementia individuals. Int. J. Geriatr. Psychiatry 1 , $3-14$.

Devanand, D.P., Liu, X., Tabert, M.H., Pradhaban, G., Cuasay, K., Bell, K., et al., 2008. Combining early markers strongly predicts conversion from mild cognitive impairment to Alzheimer's disease. Biol. Psychiatry 64, 871-879.

Koss, E., Weiffenbach, J.M., Haxby, J.V., Friedland, R.P., 1988. Olfactory detection and identification performance are dissociated in early Alzheimer's disease. Neurol. Wolters Kluwer Health, Inc. Am. Acad. Neurol. 38 1228-1228.

Elisabeth, K., 1986. Olfactory Dysfunction in Alzheimer's Disease. Taylor \& Francis Grouphttps://doi.org/10.1080/87565648609540332.

Murphy, C., Gilmore, M.M., Seery, C.S., Salmon, D.P., Lasker, B.R., 1990. Olfactory thresholds are associated with degree of dementia in Alzheimer's disease. Neurobiol Aging 11, 465-469.

Doty, R.L., Shaman, P., Dann, M., 1984. Development of the university of pennsylvania smell identification test: a standardized microencapsulated test of olfactory function [Internet]. Physiol. Behav. 489-502. https://doi.org/10.1016/0031-9384(84) 90269-5.

Hummel, T., Sekinger, B., Wolf, S.R., Pauli, E., Kobal, G., 1997. "Sniffin" sticks': olfactory performance assessed by the combined testing of odour identification, odor discrimination and olfactory threshold [Internet]. Chem. Senses 39-52. https://doi.org/ 10.1093/chemse/22.1.39.

Quarmley, M., Moberg, P.J., Mechanic-Hamilton, D., Kabadi, S., Arnold, S.E., Wolk, D.A., et al., 2016. Odor identification screening improves diagnostic classification in incipient alzheimer's disease [Internet]. J. Alzheimer Dis. 1497-1507. https://doi.org/ 10.3233 /jad-160842.

Doty, R.L., Marcus, A., Lee, W.W., 1996. Development of the 12-item cross-cultural smell identification test (CC-SIT). Laryngoscope. 106, 353-356.

Tabert, M.H., Liu, X., Doty, R.L., Serby, M., Zamora, D., Pelton, G.H., et al., 2005. A 10 item smell identification scale related to risk for Alzheimer's disease. Ann. Neurol. 58, $155-160$.

Nordin, S., Brämerson, A., Lidén, E., 1998. Bende m. The Scandinavian OdorIdentification test: development, reliability, validity and normative data. Acta Otolaryngol. 118, 226-234.

Olofsson, J.K., Josefsson, M., Ekström, I., Wilson, D., Nyberg, L., Nordin, S., et al., 2016. Long-term episodic memory decline is associated with olfactory deficits only in carriers of ApoE- $€$ 4. Neuropsychologia. 85, 1-9.

Kobayashi, M., 2005. The odor stick identification test for the japanese (OSIT-J): clinical suitability for patients suffering from olfactory disturbance. Chem. Senses 30 , i216-i217 Oxford University Press.

Murphy, C., Anderson, J.A., Markison, S., 1994. Psychophysical assessment of chemosensory disorders in clinical populations [Internet]. Olfaction and Taste XI. 609-613. https://doi.org/10.1007/978-4-431-68355-1_251.

Schubert, C.R., Carmichael, L.L., Murphy, C., Klein, B.E.K., Klein, R., Cruickshanks, K.J., 2008. Olfaction and the 5-Year incidence of cognitive impairment in an epidemiological study of older adults [Internet]. J. Am. Geriatr. Soc. 1517-1521. https://doi. org/10.1111/j.1532-5415.2008.01826.x. 